\title{
Effects of glucose, ethanol and acetic acid on regulation of ADH2 gene from Lachancea fermentati
}

Norhayati Yaacob, Mohd Shukuri Mohamad Ali, Abu Bakar Salleh, Nor Aini Abdul Rahman

Background. Not all yeast alcohol dehydrogenase $2(\mathrm{ADH} 2)$ are repressed by glucose, as reported in Saccharomyces cerevisiae. Pichia stipitis $\mathrm{ADH} 2$ is regulated by oxygen instead of glucose, whereas Kluyveromyces marxianus ADH2 is regulated by neither glucose nor ethanol. For this reason, $\mathrm{ADH} 2$ regulation of yeasts may be species dependent, leading to a different type of expression and fermentation efficiency. Lachancea fermentati is a highly efficient ethanol producer, fast-growing cells and adapted to fermentation-related stresses such as ethanol and organic acid, but the metabolic information regarding the regulation of glucose and ethanol production is still lacking. Methods. Our investigation started with the stimulation of ADH2 activity from $S$. cerevisiae and $L$. fermentati by glucose and ethanol induction in a glucose-repressed medium. The study also embarked on the retrospective analysis of $\mathrm{ADH} 2$ genomic and protein level through direct sequencing and sites identification. Based on the sequence generated, we demonstrated ADH2 gene expression highlighting the conserved $N A D(P)$-binding domain in the context of glucose fermentation and ethanol production. Results. An increase of ADH2 activity was observed in starved $L$. fermentati (LfeADH2) and S. cerevisiae (SceADH2) in response to $2 \%(w / v)$ glucose induction. These suggest that in the presence of glucose, ADH2 activity was activated instead of being repressed. An induction of $0.5 \%(\mathrm{v} / \mathrm{v})$ ethanol also increased LfeADH2 activity, promoting ethanol resistance, whereas accumulating acetic acid at a later stage of fermentation stimulated ADH2 activity and enhanced glucose consumption rates. The lack in upper stream activating sequence (UAS) and TATA elements hindered the possibility of Adr1 binding to LfeADH2. Transcription factors such as SP1 and RAP1 observed in LfeADH2 sequence have been implicated in the regulation of many genes including $A D H 2$. In glucose fermentation, $L$. fermentati exhibited a bell-shaped ADH2 expression, showing the highest expression when glucose was depleted and ethanol-acetic acid was increased. Meanwhile, S. cerevisiae showed a constitutive ADH2 expression throughout the fermentation process. Discussion. $A D H 2$ expression in $L$. fermentati may be subjected to changes in the presence of non-fermentative carbon source. The nucleotide sequence showed that $\mathrm{ADH} 2$ transcription could be influenced by other transcription genes of glycolysis oriented due to the lack of specific activation sites 
for Adr1. Our study suggests that if Adr1 is not capable of promoting LfeADH2 activation, the transcription can be controlled by Rap1 and Sp1 due to their inherent roles. Therefore in future, it is interesting to observe $\mathrm{ADH} 2$ gene being highly regulated by these potential transcription factors and functioned as a promoter for yeast under high volume of ethanol and organic acids. 
1

2

3

4

5

6

8

9

10

11

12

13

14

15

16

17

21

\section{Effects of glucose, ethanol and acetic acid on regulation of ADH2 gene from Lachancea fermentati}

Norhayati Yaacob ${ }^{1,2}$, Mohd Shukuri Mohamad Ali ${ }^{1,2}$, Abu Bakar Salleh, ${ }^{1,2}$ and Nor 'Aini Abdul $\operatorname{Rahman}^{3}$

1. Enzyme and Microbial Technology Research Centre, Universiti Putra Malaysia, 43400 Serdang, Malaysia

2. Department of Biochemistry, Faculty of Biotechnology and Biomolecular Sciences, Universiti Putra Malaysia, 43400 Serdang, Malaysia

3. Department of Bioprocess Technology, Faculty of Biotechnology and Biomolecular Sciences, Universiti Putra Malaysia, 43400 Serdang, Malaysia

*Corresponding author. Tel: $+603-89466721$

Fax: $+603-89430913$

Email address: mshukuri@upm.edu.my 
30 ABSTRACT

32 Background. Not all yeast alcohol dehydrogenase 2 (ADH2) are repressed by glucose, as reported

33 in Saccharomyces cerevisiae. Pichia stipitis ADH2 is regulated by oxygen instead of glucose,

34 whereas Kluyveromyces marxianus ADH2 is regulated by neither glucose nor ethanol. For this

35 reason, $\mathrm{ADH} 2$ regulation of yeasts may be species dependent, leading to a different type of 36 expression and fermentation efficiency. Lachancea fermentati is a highly efficient ethanol

37 producer, fast-growing cells and adapted to fermentation-related stresses such as ethanol and 38 organic acid, but the metabolic information regarding the regulation of glucose and ethanol 39 production is still lacking.

41 Methods. Our investigation started with the stimulation of ADH2 activity from $S$. cerevisiae and 42 L. fermentati by glucose and ethanol induction in a glucose-repressed medium. The study also 43 embarked on the retrospective analysis of $\mathrm{ADH} 2$ genomic and protein level through direct 44 sequencing and sites identification. Based on the sequence generated, we demonstrated ADH2 gene expression highlighting the conserved NAD(P)-binding domain in the context of glucose 46 fermentation and ethanol production.

Results. An increase of ADH2 activity was observed in starved L. fermentati (LfeADH2) and $S$. cerevisiae $(\mathrm{Sce} \mathrm{ADH} 2)$ in response to $2 \%(\mathrm{w} / \mathrm{v})$ glucose induction. These suggest that in the presence of glucose, $\mathrm{ADH} 2$ activity was activated instead of being repressed. An induction of $0.5 \%$

51 (v/v) ethanol also increased LfeADH2 activity, promoting ethanol resistance, whereas 52 accumulating acetic acid at a later stage of fermentation stimulated ADH2 activity and enhanced 
53 glucose consumption rates. The lack in upper stream activating sequence (UAS) and TATA

54 elements hindered the possibility of Adr1 binding to LfeADH2. Transcription factors such as SP1

55 and RAP1 observed in LfeADH2 sequence have been implicated in the regulation of many genes

56 including $\mathrm{ADH} 2$. In glucose fermentation, L. fermentati exhibited a bell-shaped ADH2 expression,

57 showing the highest expression when glucose was depleted and ethanol-acetic acid was increased.

58 Meanwhile, S. cerevisiae showed a constitutive ADH2 expression throughout the fermentation 59 process.

61 Discussion. ADH2 expression in L. fermentati may be subjected to changes in the presence of

62 non-fermentative carbon source. The nucleotide sequence showed that ADH2 transcription could

63 be influenced by other transcription genes of glycolysis oriented due to the lack of specific

64 activation sites for Adr1. Our study suggests that if Adr1 is not capable of promoting LfeADH2

65 activation, the transcription can be controlled by Rap1 and Sp1 due to their inherent roles.

66 Therefore in future, it is interesting to observe $\mathrm{ADH} 2$ gene being highly regulated by these

67 potential transcription factors and functioned as a promoter for yeast under high volume of ethanol 68 and organic acids.

\section{INTRODUCTION}

Lachancea sp, a type of yeast, is no stranger to the study of alcohol dehydrogenase (ADH) gene

73 isolations and biochemical characterizations. A decade ago, ethanol metabolism in Lachancea sp.

74 has been studied by Duarte et al. (2004) via enzyme profiling showing the differences in ADH

75 isoenzymes which could be observed across Lachancea species. ADH catalyzes the final metabolic 
76 step in ethanol fermentation and plays an important role for general metabolic pathways of yeast

77 to yield energy as well as to proliferate under anaerobic conditions (Liang et al., 2014).

L. fermentati was a former member of Kluyveromyces, Saccharomyces and Zygosaccharomyces

(Kurtzman. 2003). The identification of L. fermentati was based on the evaluation from the

perspective of the multigene sequence analysis which resulted in the reassignment of Lachancea

$s p$. The haploid number of chromosomes in Lachancea $s p$. is reported to be 8 , equivalent to half

of the haploid chromosome numbers of Saccharomyces and Kluyveromyces (Naumova et al., 2007).

85

To date, L. fermentati is known for its efficient role in ethanol fermentation (Natararajan et al.,

87 2012). However, there is a lack of information regarding the metabolic and gene regulations that took place during the glucose fermentation of Lachancea sp. (Thomson et al., 2013). In this study, ethanol, glucose, and acetic acid are investigated for their role in regulating L. fermentati ADH2 expression. This enzyme would then be compared to the expression of common yeast, S. cerevisiae

$91 \mathrm{ADH} 2$ in terms of repression and derepression mechanism in relation to carbon sources. Glucose repression and derepression essentially concern genes involved in oxidative metabolism

93 (Weinhandl et al., 2014). In fermentation, yeast cells accumulate fermentation products, such as

94 ethanol, from sugars. Then, this was accompanied by an increase in medium acidity, due to the 95 secretion of organic acids at the later stage of fermentation. The pathway associated with stress 96 response in yeast, in line with ethanol and acetic acid production, proved to be deadly, as they 97 demonstrate inhibition of cell growth and represses glucose transport (Burtner et al., 2009). 98 Because ADH2 gene is highly deregulated by glucose, it can control both of the respiration and 
99 metabolism function through it's role in aerobic respiration and mitochondrial function. This

100 makes the gene one of the suitable targets for its ethanol and organic acid tolerance. As for this

101 reason, $\mathrm{ADH} 2$ can become an important marker in determining the beginning of glucose, ethanol

102 and acetic acid stress activity (Denis et al., 1983; Smidt et al., 2008; Lin et al., 2010).

103

104 The gene can also be linked to the function of hexokinase and other glycolytic genes as it has been 105 demonstrated having a promoter activity based on the glucose stimulation (Lee et al. 2005;

106 Weinhandl et al. 2014). The long-term advantage of utilizing ADH2 gene as a promoter compared

107 to the other common used promoters is that no specific inducer is required. In the case when an

108 increase of biomass concentration was evident, the ADH2 gene has shown a high level of

109 expression which is appropriate in the optimization of bioethanol fermentation (Weinhandl et al., 110 2014).

The mechanism of yeast stress tolerance was extensively studied in S.cerevisiae as

113 compared to other yeasts. It was reported that $S$. cerevisiae could tolerate various types of stresses

114 in particular of ethanol inhibition and osmotic pressure from acids and sugars from bioethanol

115 production (Zhao and Bai, 2009). The latest development of stress tolerance mechanisms was

116 focused more on the genomics rather than proteomics as it quick to point out the causes of these

117 adverse conditions. However, the mechanism of yeast stress tolerance through correlation of

118 biological response with the flux of gene expression under the presence of stress is equally

119 important as it elaborates the genetic dependence of stress on the external stimuli of fermentation.

120 Hence, by comparing the expression of ADH2 before and after the induction of these stresses, the

121 role of $\mathrm{ADH} 2$ can be evaluated. Besides the observation of genes expression to demonstrate 
122 environmental liability that potentially leads to the early sign of stress, it is also vital to know the

123 habitual of genes expressed under a favorable condition for example when glucose is in abundance.

124

125

Despite these well-known characteristics, De Smith et al., (2012) reported that ADH2 was

126 not fully repressed even in the presence of glucose, as the gene transcription could still be detected

127 in glucose-laden condition. This could be due to the upstream activation sequences (UAS1 and

128 UAS2) located at the C-terminal of ADH2 sequences. Both of them are necessary for the complete

129 derepression of $\mathrm{ADH} 2$ which requires activation by trans-acting regulatory element, Adr1p (Smidt

130 et al., 2008). For UAS2, the activation (derepression) of ADH2 expression is highly dependent on

131 its orientation and copy numbers. However, when UAS2 is disorientated, a decline of ADH2

132 expression will be observed as it acts synergistically with UAS1 as a binding site for Adr1p to

133 stimulate the expression of ADH2 (Smidt et al., 2008; De Smith et al., 2012). Thus, the uses of

$134 \mathrm{ADH} 2$ as a promoter for bioethanol production could be based on its characteristics in the

135 repression and derepression mechanism (Donoviel et al., 1995; Smidt et al., 2008). The choice of

136 the right promoter is a crucial point for efficient gene expression, as most regulations take place at

137 the transcriptional level (Weinhandl et al., 2014).

138

An over-expression of ADH2 is capable of exhibiting a continuous cell growth in ethanol

140 and is important for the control of the glucose uptake. The increase of ADH2 activity also results

141 in the increase of acetic acid production which negatively affects the fermentation, leading to a

142 sluggish or arrested fermentation (Maestre et al., 2008). As ADH2 expression increased

143 (derepression), the accumulation of ethanol within the cell is likely to be responsible for the rapid

144 fermentation at $30^{\circ} \mathrm{C}$, influencing high cell density and acetic acid production (Nagodawithana et 
145 al., 1976). The transcription of yeast $\mathrm{ADH} 2$ in a regulation of the external environment of

146 fermentation is a very interesting subject, as it supports in the description of the mechanism

147 involved in various biotechnological processes (Cho et al., 2009; Lin et al., 2010). In this study,

148 we analyzed the sequence harboring the ADH2 gene from L. fermentati, identify its regulatory

149 genes and transcription binding sites, followed by determination of ADH2 regulation in the

150 presence of glucose, ethanol, and acetic acid.

151

\section{MATERIALS AND METHODS}

153

154 Yeast strains validation and culture conditions

155 S. cerevisiae obtained from a commercially produced yeast powder was used as a control in this

156 study as it demonstrates ethanol fermentation ability in high glucose content $(10 \%, \mathrm{v} / \mathrm{v})$. This is an

157 important criterion in order to observe the expression or activity of a glucose-regulated ADH2

158 gene. L. fermentati was isolated from a fermented nypa sap of Nypa fruticans located in Telok

159 Intan, Malaysia (Natarajan et al., 2012). The Internal transcribed spacer (ITS) regions (comprising

160 partial sequence 18S rDNA-ITS1-5.8S rDNA-ITS2- partial sequence 28S rDNA) of the selected

161 yeasts were amplified and sequenced for species and strain identification purposes using the

162 methods of Fujita et al. (2003). Based on the BLAST analysis, the ITS nucleotide sequences of $S$.

163 cerevisiae exhibited 98 to $99 \%$ similarity with the $S$. cerevisiae of Chicha strain (KC183723.1).

164 As expected, the L. fermentati ITS sequence exhibited a 100\% similarity with the strain SHM1

165 (accession number JN674449.1). Yeast Peptone Dextrose (YPD) medium (1\% yeast extract, 2\%

166 peptone, and $2 \%$ glucose) was used for the culture maintenance at $30^{\circ} \mathrm{C}$. 
168 Partial ADH2 amplification and phylogenetic analysis

169 Both L. fermentati and S. cerevisiae were subjected to partial ADH2 PCR amplification by using

170 denatured primer (Table 1). The ADH2 gene from L. fermentati strain SHM1 was designed based

171 on the validated alcohol dehydrogenase sequences of Saccharomyces and Lachancea origins

172 highlighting the conserved region. The amplification procedure was performed in $20 \mu 1$ reaction

173 with pre-denaturation of $95^{\circ} \mathrm{C} ; 5 \mathrm{~min}$, followed by 30 cycles of denaturation $95^{\circ} \mathrm{C} ; 30 \mathrm{sec}$,

174 annealing $55^{\circ} \mathrm{C} ; 30 \mathrm{sec}$, pre-elongation $72^{\circ} \mathrm{C} ; 30 \mathrm{sec}$, and final elongation $72^{\circ} \mathrm{C}$; for $5 \mathrm{~min}$. The

175912 bp length of ADH2 gene obtained from wild-type L. fermentati were excised and purified

176 using QIAquick Gel Extraction Kit (QIAGEN, Germany), before submitted for DNA sequencing

177 (1 ${ }^{\text {st }}$ Base Sdn Bhd, Malaysia). The deposited nucleotide sequences (accession number: KU203771)

178 were then translated into peptide sequences using a translational tool from ExPASy (SIB,

179 Switzerland) and peptide alignments were performed by using SDSC Biology Workbench 3.2.

180 Phylogenetic analysis based on the model of Pearson and the neighbor-joining analysis was

181 performed with 1000 replicates of bootstrap test by using MEGA 6.06 software.

182

183 Total RNA extraction and cDNA synthesis

184 Total RNA was extracted using the Presto ${ }^{\mathrm{TM}}$ Mini RNA Yeast Kit (Geneaid, Taiwan) following

185 the protocol provided by the manufacturer. RNA concentration and quality were determined using

186 the $\mathrm{A}_{260} / \mathrm{A}_{280}$ spectrophotometric absorption ratio (Eppendorf, Germany) and RNA Bioanalyzer

1872100 Plant Nano chip (Agilent, USA) to determine the RNA integration number (RIN) values. The

188 RNA quality was also tested by electrophoresis on $1 \%(\mathrm{w} / \mathrm{v})$ agarose gel. cDNA was synthesized

189 from the isolated high-quality RNA by using one-step RT-qPCR iScript ${ }^{\mathrm{TM}}$ reverse transcription 190 supermix (BioRad, USA). 


\section{Real time-PCR primer design}

193 A complete nucleotide sequence of Saccharomyces cerevisiae ADH2 was available at the

194 Saccharomyces cerevisiae Genome Database (http://www.yeastgenome.org/). The primers for $S$.

195 cerevisiae were designed by using the software Primer Express (Applied Biosystems, Foster City,

196 USA), while the primers for L. fermentati were designed based on the multi-alignment of ADH2

197 gene sequences from the Saccharomyces, Kluyveromyces, and Lachancea families. Actin1

198 (ACT1) was chosen as the reference gene for normalizations (Ismail et al., 2013). Real-time PCR

199 Table 1 showed the primer sequences used for gene expression along with their amplicon sizes.

200

201 Gene expression analysis with real-time PCR

202 ADH2 gene expression was determined by real-time PCR. An efficiency test was performed using 203 cDNA from $S$. cerevisiae and L. fermentati as the template. The PCR efficiency was scaled to 95$204105 \%$ and above, 0.999 R-squared and a slope of -3.33, as recommended (Bustin et al., 2009).

205 Real-time PCR assays were performed in an iCycler (iQ⿱一𫝀口5, BioRad, USA), using the standard 206 thermal cycling protocol. The reaction mixture of $20 \mu 1$ contained $10 \mu 1$ of iTaq Universal SYBR $\mathbb{R}$

207 Green Supermix (2x) (BioRad, USA), $0.75 \mathrm{nM}$ of forward and reverse primers, $2 \mu 1$ of 10-fold 208 diluted cDNA, and deionized water to reach the final volume. Real-time PCR experiments were 209 carried out in two replicates, of which each real-time PCR was performed in duplicate on each

210 sample. A negative control without the cDNA template was included. The thermal amplification 211 program used was as follows: $95^{\circ} \mathrm{C}$ for $30 \mathrm{~s} ; 40$ cycles of $95^{\circ} \mathrm{C}$ for $10 \mathrm{~s}$; and $60^{\circ} \mathrm{C}$ for $30 \mathrm{~s}$ before

212 the melt-curve was collected from $58^{\circ} \mathrm{C}$ to $90^{\circ} \mathrm{C}$. Figure $1 \mathrm{~S}$ displayed melt curve analysis for

213 ADH2 and Act1 genes during the amplification. Gene expression levels were shown as the 
214 threshold cycle $\left(\mathrm{C}_{t}\right)$ of the studied gene normalized with the $\mathrm{C}_{t}$ of a reference gene, ACT1 (Table 215 1S).

216

\section{Induction of $\mathbf{A D H} 2$}

218 In ADH2 protein induction study, $2 \%\left(\mathrm{wv}^{-1}\right)$ glucose (for repression) and $0.5 \%\left(\mathrm{vv}^{-1}\right)$ ethanol (for

219 derepression) were added in $100 \mathrm{ml}$ of YPD medium at $30^{\circ} \mathrm{C}$ with $200 \mathrm{rpm}$ of agitation after $24 \mathrm{~h}$ 220 because there was no glucose remained in the medium. Following the induction, fermentation was 221 extended for one hour before cells were completely harvested and protein was extracted for ADH2 222 activity determination.

224 Intracellular protein extraction

225 The cell was harvested from the culture and washed two times with deionized water. Then, the 226 protein extract was prepared by mixing $20 \mathrm{ml}$ of $50 \mathrm{mM}$ phosphate buffer ( $\mathrm{pH}$ 7.8). The cell 227 suspension was lysed via the sonication method (Branson, USA) for $2.5 \mathrm{~min}$, with $5 \mathrm{sec}$ of pulses. 228 The supernatant was collected as protein extract after $10 \mathrm{~min}$ of centrifugation at $8000 \mathrm{Xg}$ with a 229 temperature of $4^{\circ} \mathrm{C}$. Total protein concentration was determined by the method of Bradford (Quick 230 Start $^{\mathrm{TM}}$ Bradford, BioRad), as specified by the manufacturer.

\section{ADH2 screening assay}

233 The unpurified soluble protein extracted from S. cerevisiae and L. fermentati cells were used in 234 the measurement of $\mathrm{ADH} 2$ activity. The reaction for $\mathrm{ADH} 2$ assay was performed in $0.3 \mathrm{ml}$ of total 235 volume containing $20 \mathrm{mM}$ of sodium pyrophosphate buffer ( $\mathrm{pH} 7.8), 3.3 \%(\mathrm{v} / \mathrm{v})$ of ethanol, 7.5 $236 \mathrm{mM}$ of $\mathrm{NAD}^{+}$and $<10 \mu \mathrm{g}$ of $\mathrm{ADH}$ (protein), with 7 to 8 min of reaction time. ADH2 activity was 
237 measured by increasing $340 \mathrm{~nm}$ absorbance in response to NADH or acetaldehyde production. The 238 units/ml of ADH2 activity was calculated by using 6.22 of the millimolar extinction coefficient of

$239 \beta-\mathrm{NADH}$ at $340 \mathrm{~nm}$. One unit of $\mathrm{NAD}^{+}$converts $1.0 \mu$ mole of ethanol to acetaldehyde per minute

240 at $\mathrm{pH} 7.8$ and $25^{\circ} \mathrm{C}$ (Kägi et al., 1960). ADH activity was also qualitatively measured via native

241 PAGE by adding ADH activity buffer containing $4.0 \mathrm{mg}$ of phenazine methyl sulfate (Sigma-

242 Aldrich, Germany), $10 \mathrm{mg}$ of nitroblue tetrazolium (Sigma-Aldrich, Germany), $50 \mathrm{mg}$ of NAD ${ }^{+}$

243 (Sigma, Germany) and $0.05 \mathrm{ml}$ of absolute ethanol dissolved in $50 \mathrm{ml}$ of $0.1 \mathrm{M}$ Tris- $\mathrm{HCl}$ buffer

$244(\mathrm{pH} 8.5)$ until the desired purple staining was formed (Young et al., 2000).

\section{Shake flask fermentation}

247 Seed cultures of S. cerevisiae and L. fermentati were grown at $30^{\circ} \mathrm{C}, 200 \mathrm{rpm}$ agitation speed for $24824 \mathrm{~h}$ in a universal tube containing $10 \mathrm{ml}$ of the YPD medium and then inoculated into the 249 fermentation medium at a level of $1 \%\left(\mathrm{v} \mathrm{v}^{-1}\right)$. The fermentation medium of $2 \%$ YPD (1\% yeast 250 extract, $2 \%$ peptone, and $2 \%$ glucose) was prepared at $100 \mathrm{ml}$ in a $500 \mathrm{ml}$ Erlenmeyer flask, where 251 the fermentations were all carried out in similar condition. Before the fermentation, the starting 252 density $\left(\mathrm{OD}_{600}\right)$ of all cultures was 0.5 . Over the course of the $30 \mathrm{~h}$ fermentation, samples were 253 collected every $6 \mathrm{~h}$ to monitor the growth, ethanol, organic acid and residual glucose 254 concentrations. Repeats were performed in triplicate. The fermentation products were centrifuged 255 at $8000 \mathrm{X}$ g for $10 \mathrm{~min}$ to separate the cells from the analytes. The supernatants were stored at $25620^{\circ} \mathrm{C}$ until used for the ethanol and glucose assays while the precipitants were used in the RNA 257 extraction and $\mathrm{ADH}$ assays.

259 Determination of ethanol and glucose concentration 
260 The content of the ethanol in the fermentation samples was determined based on the 96-microwell

261 plate system using the ethanol extraction method (Seo et al. 2009). The sugar concentration was

262 determined using the 3, 5-dinitrosalicylic acid (DNS) method (Bernfeld., 1955).

263

264 Acetic acid production determination

265 Analyzes of organic acids, such as ethanoic acid (acetic acid) were performed by High266 Performance Liquid Chromatography, using an Agilent Poroshell 120 EC-C18 column. The 267 column and mobile phase line of the instrument were thoroughly washed with $50 \%$ 268 Acetonitrile $/ 50 \%$ water of mobile solution. The running buffer or eluent that was used to detect 269 weak acids contained $1 \mathrm{mmol} / \mathrm{l}$ of sulfuric acid and $8 \mathrm{mmol} / \mathrm{l}$ of $\mathrm{Na}_{2} \mathrm{SO}_{4}$, with $\mathrm{pH} 2.8$. The flow 270 rate of the mobile phase was adjusted to $0.9 \mathrm{ml} / \mathrm{min}$ and the temperature was fixed at $25^{\circ} \mathrm{C}$.

271

272 RESULTS AND DISCUSSION

273

274 Derepression of ADH2 by glucose induction

275 While the era of yeast synthetic biology began in the well-characterized model organism $S$. 276 cerevisiae, other non-conventional yeast production systems such as Hansenula polymorpha, 277 Kluyveromyces lactis, Pichia pastoris, and Yarrowia lipolytica have been regarded as a eukaryote 278 model with growing importance (Wagner and Alper. 2015). These yeasts including L. fermentati 279 have roles in the manufacture of vaccines, therapeutic proteins, food additives, and renewable 280 chemicals, but recent synthetic biology advances have the potential to greatly expand and diversify 281 their impact on biotechnology, which is how the potential of ADH2 gene from L. fermentati 
282 (LfeADH2) can provide an alternative biomanufacturing platforms primarily as a promoter. To

283 date, L. fermentati has not yet been widely considered for industrial usages.

284

285 During induction at the glucose-limiting period, ADH2 from L. fermentati exhibited higher affinity

286 for glucose and ethanol, as shown by a 2.5 -fold increase in $0.5 \%\left(\mathrm{vv}^{-1}\right)$ ethanol and 0.5 -fold

287 increase in $2 \%\left(\mathrm{wv}^{-1}\right)$ glucose (Figure 1). However, $S$. cerevisiae ADH2 activity was increased by

288 1.3-fold following the addition of $2 \%$ glucose, and was repressed by 0.5 -fold with the addition of

$2890.5 \%$ ethanol. Based on the results obtained, ADH2 protein from Saccharomyces cerevisiae did

290 not exhibit a strong glucose-repressible activity.

291

292 ADH2 activity staining using the ADH2 protein confirmed the outcomes of ADH2 activity after

293 the sugar and non-sugar-based induction. The degradation of ethanol as a substrate by this protein-

294 entrapped in native polyacrylamide gel can be measured by its intensity after staining. Based on

295 these results, it can be implied that both glucose and ethanol shared significant roles in the

296 derepression or activation mechanism of L. fermentati ADH2 promoter.

297

298 This experiment demonstrated that both ADH2 enzyme activity and protein expression shifted

299 with the addition of ethanol or glucose into the medium. In previous work by Irani et al. (1987),

300 ADH2 from $S$. cerevisiae was undetectable in the presence of a fermentable carbon source such as

301 glucose, but when glucose was exhausted from the medium or when the cells are grown on a non-

302 fermentable carbon source such as ethanol, ADH2 enzyme activity, and mRNA are present in large

303 amounts. The results were connected to Denis et al. (1983), which described contradicting changes

304 in S. cerevisiae ADH1 expression resulting an increase of mRNA levels when ethanol grown-cells 
305 were transferred into medium containing glucose (Tornow and Santangelo., 1990). Therefore, it is

306 not surprising that both $\mathrm{ADH} 1$ and $\mathrm{ADH} 2$ have been widely accepted as a promoter in yeast for

307 their regulation according to a specific carbon source. In this study, ADH2 gene from L. fermentati

308 strain SHM1 has been found to be regulated by both glucose and ethanol, an interesting concept

309 of a two-in-one promoter system.

310

311 Previously, S. cerevisiae ADH2 promoter is not the only alcohol dehydrogenase promoter

312 that has been used in the study of glucose-related expression. Fission yeast S. pombe ADH2

313 promoter which showed high homology at the protein level to S. cerevisiae ADH2 also was

314 frequently utilized as a promoter. Unlike $S$. cerevisiae, $S$. pombe ADH2 was constitutively

315 expressed that resulted in the up-regulation of $\mathrm{ADH} 2$ transcription in the presence of glucose

316 (Russel and Hall., 1983). Contradict to that, K. marxianus strain IFO 1802 ADH2 (KmADH2)

317 exhibited a low expression level in high glucose and ethanol throughout the $72 \mathrm{~h}$ of $150 \mathrm{~g} / \mathrm{L}$ glucose

318 fermentation (Liang et al., 2014). Overall, the stringency of yeast ADH2 activation and expression

319 towards the glucose availability was rather obscure. There are mutants that allowed ADH2

320 expression to escape glucose-repression in which, a rare-semidominant Adr1 allele (constitutive)

321 is involved. The constitutive Adr1 showed mutations between amino acids 227 and 239 was said

322 to be caused by a post-translational inhibition (Ratnakumar et al., 2009). Inclusive to our findings,

323 the glucose induction reflects the possibility of ADH2 to be express in the presence of glucose. It

324 means that glucose and ethanol would have the ability to promote ADH2 expression in $L$.

325 fermentati. This result was contradicted to $K$. marxianus $\mathrm{ADH} 2$ where the protein was unable to

326 be expressed in the presence of either of this compound. 
328 Based on these findings, we performed some retrospective analysis on sequences bearing $L$.

329 fermentati ADH2-like sequences highlighting on the presence of transcription binding sites which

330 probably involved in the activation of ADH2 transcription.

331

332 Multiple alignments of partial ADH peptide sequences

333 The partial ADH gene amplifications were initiated by using a pair of denatured primer (Table 1).

334 The primer sequences were designed based on the multi-alignment of verified ADH2 nucleotide 335 sequences from Saccharomyces and Lachancea species. To date, there are no alcohol 336 dehydrogenase sequences available in NCBI database for L. fermentati. Thus, we amplified and 337 sequenced ADH2 gene from L. fermentati (previously known as Zygosaccharomyces fermentati) 338 for the first time. The 912 bp-length ADH2 nucleotide sequences amplified from L. fermentati was 339 very different from the well-known yeast ADH2 sequences. The highest similarity score of ADH2 340 sequences amplified from L. fermentati strain SHM1 (KU203771) was 88.6\% with L. kluyveri

341 ADH2 (AAP51047.1). The nucleotide sequences and motifs observed in ADH2 gene in $L$.

342 fermentati were highly conserved. But the analysis showed that there were a few variations found 343 to the other existing ADH2 sequences from different species. Figure 2 showed the multiple 344 alignments of various $\mathrm{ADH} 2$ protein sequences together with $\mathrm{ADH} 2$ gene from $L$. fermentati. The 345 analysis of ADH2 sequences from L. fermentati successfully identified the highly preserved amino 346 acids and the zinc-binding motifs. Based on the protein alignments, several residues were believed 347 to have a species-related function as observed in Iso-37, Glu-117, Glu-175, Cys-183, Thr-228, 348 Val-231 and Gly-276. It is, therefore, important to study on the role of these residues toward the 349 expression of this gene as they could provide be a useful indication on the nature of regulation of 350 this protein. In this assignment, Thr-228 and Val-231 were the residues included in sequences for 
351 gene expression throughout the yeast fermentation study. Typically the HXXXH motifs containing

352 imidazole ring has been well described in yeast as the site where metal ion exchange happens in

353 zinc-containing enzymes. Currently, both S. cerevisiae and L. fermentati exhibited conservation

354 of this zinc binding sites at residues 48-55 based on the HXXXH motif and residues 64-74

355 according to the Interpro analysis (Obradors et al., 1998).

356

357 The neighbor-joining phylogenetic analysis of ADH2 nucleotide sequences from L. fermentati 358 strain SHM1 exhibited highest similarity to ADH2 gene belonged to L. kluyveri followed by the

359 Saccharomyces family. A slight distance from L. fermentati observed in the phylogenetic tree 360 indicated the distribution of Kluyveromyces and another different Lachancea cluster family, where

361 this isolated cluster of Lachancea group contained the uncharacterized ADH2 sequence. Hence,

362 L. fermentati $\mathrm{ADH} 2$ was presumed to inherit considerable genomic characteristics from the

363 Saccharomyces and Kluyveromyces origins (Figure 3).

364

365 The transcription binding site in partial ADH2 sequences of $L$. fermentati

366 Yeast $\mathrm{ADH} 2$ was known to repress growth on fermentative carbon sources and have a lower

367 affinity for glucose (Kachevrovsky et al., 2008). The results of glucose-inducible ADH2

368 contradicted the normal regulation of glucose-repressible ADH2, as observed in real-time PCR,

369 indicating that $\mathrm{ADH} 2$ transcription was not glucose-dependent. To date, it is known that the

370 glucose-regulated $\mathrm{ADH} 2$ gene was activated by several regulating genes. Among these genes is

371 Adr1, which binds to the ADH2 promoter site at upper-activating sequence (UAS). When glucose

372 was added, the established Adr1-UAS1 binding weakened, as Adr1 was inhibited by glucose,

373 which, in turn, repressed ADH2, causing minimal expression or activity (Irani et al., 1987; Young 
374 et al., 2000). However, Young et al., (2008) reported that Adr1 competently binds to the specific

375 UAS sequence even when glucose levels are still high, which may be a possible reason for the

376 high ADH2 activity observed after glucose was added. Alternatively, the increase in Adr1

377 synthesis could also cause $\mathrm{ADH} 2$ to express constitutively during growth on glucose. This

378 condition allows ADH2 expression to escape glucose repression (Irani et al., 1987). However so,

379 this type of regulation had only been studied in S. cerevisiae and has not been evaluated for other

380 kinds of yeast species. Figure 4 demonstrates that the conservation of Adr1-binding site was not

381 always significant for glucose-regulated genes as most of the ADH2 sequences from yeast which

382 belonged to non-Saccharomyces group possessed no inherent Adr1-binding sites. A multiple

383 sequence alignment of ADH2 proteins from P. stipitis (Y13397.1), S. cerevisiae S288c

384 (NM_001182812.1), K. marxianus (KF678866.1) and L. fermentati (KU203771) showed some

385 irregularities in the conservation sites of UAS and TATA sequences (Figure 4). Nucleotide

386 sequence analysis showed that $P$. stipitis and $S$. cerevisiae possessed UAS and TATA repeats while

387 K. marxianus and L. fermentati did not.

388

389

In S. cerevisiae, the presence of large excess of competing promoter elements such as UAS

and TATA regions were important to ensure the competency of ADH2 promoter (Irani et al.,

391 1987). The involvement of Adr1 transcription factor to promote ADH2 expression was primarily

392 based on the conservation of UAS1 and UAS2 regions. The ADH2 promoter which lacked the

393 upstream regulatory region has been reported to cause in inactivation, while the missing of TATA

394 box in the sequence was reported to contribute to an intermediate level of binding competition

395 (Irani et al., 1987). It is worth to note that the control of Adr1 binding does not only occur at the

396 gene transcriptional level but also during the post-translational modification of the protein as well 
397 (Irani et al., 1987; Kachevrovsky et al., 2008). Following the preliminary genomic studies, ADH2

398 gene transcription in L. fermentati might not work according to its' approach (glucose-repressible)

399 in the absence of UAS and TATA.

400

401

The presence of Adr1-binding sequence at nucleotides 99-108, 228-237, 828-839 showed

402 that $\mathrm{ADH} 2$ gene from L. fermentati would be readily transcribed. The lack in adjacent upper 403 stream-activating sequences, however, left the sequence incomplete for Adr1 binding.

404 Nonetheless, within the sequence of $\mathrm{ADH} 2$, there are other potential regulatory genes which made

405 up the complex transcriptional network in yeast. These genes which exist in abundance can

406 promote $\mathrm{ADH} 2$ regulation inadvertently providing suitable condition which stimulates them. In $L$.

407 fermentati, regulatory genes or activator-binding protein such as the zinc finger transcription factor

408 (Sp1) and repressor/activator site binding protein (Rap1) are believed to equally participate in

409 ADH2 gene regulation. Sp1 contains a highly conserved DNA-binding domain composed of three

410 zinc fingers close to the $\mathrm{C}$-terminus with serine/threonine- and glutamine-rich domains in their $\mathrm{N}$ -

411 terminal regions. This protein is an extremely versatile protein involved in the expression of many

412 different genes which differs between the cell types during development. Given that there are at

413 least 11 sites for the binding of $\mathrm{Sp} 1$ in L. fermentati $\mathrm{ADH} 2$ gene and its importance in many genes

414 activation, it is predicted that the cells would not survived without their presence. So far, little is

415 known how Sp1 act on natural promoters in combination with other transcription factors in vivo

416 (Suske., 1999; Bouwman and Philipsen., 2002).

417

418 The presence of RAP1 transcriptor factor which was known to activate most ribosomal

419 protein and glycolysis enzymes can function as a strong key promoter to ADH2 gene in the 
420 presence of glucose. The Rap1 site appears to mediate the response of these genes to the

421 appearance or disappearance of glucose; for example, their expression is coordinately down-

422 regulated upon depletion of glucose at the diauxic shift (Santangelo., 2006). The presence of

423 regulatory genes shown in Figure 5 was predicted via in-silico -based software (TRANSFAC

424 Database, Biobase, $\mathrm{GmbH}$ ) and was found to be conserved in the nucleotide sequence of ADH2

425 from L. fermentati. Therefore, ADH2 gene could harbor its function through various promoters 426 and activators without having the UAS and TATA regions to activate it through Adr1.

In general, $\mathrm{ADH} 2$ has a broader role in the yeast cell physiology and growth than

previously reported, as this gene can either be involved in the utilization of non-fermentable carbon sources, carbohydrate and nitrogen metabolism or protein synthesis depends on its type of species

431 (Cheng et al., 1994). In the quest to determine which carbon elements contributes to ADH2 432 activation in the presence of glucose, ethanol, and by-product (acid), a relative gene expression of 433 ADH2 from L. fermentati and S. cerevisiae were performed.

\section{ADH2 gene regulation}

436 In analyzing ADH2 expression, cells from S. cerevisiae and L. fermentati were harvested at 437 different growth stages. The cell harvest obtained from the basal (zero h), exponential $\left(6^{\text {th }}, 12^{\text {th }} h\right)$, 438 mid-exponential $\left(18^{\text {th }} \mathrm{h}\right)$ and stationary $\left(30^{\text {th }} \mathrm{h}\right)$ phases, along the $30 \mathrm{hr}$ length of $2 \%(\mathrm{w} / \mathrm{v})$ glucose fermentation. The regulations of $\mathrm{ADH} 2$ in both yeasts were influenced by cell growth, ethanol

440 production as well as glucose consumption as shown in Figure 6. 
443 S. cerevisiae ADH2 improved showing its activation during exponential growth phase. The trend 444 of ADH2 expression follows the order of consumption and ended with ethanol as well as by445 products production. The availability of glucose can influence the repression of ADH2 in the 446 waking phase of fermentation. But once the glucose had been completely used up, ethanol or even

447 acetate would take up the role of $\mathrm{ADH} 2$ derepression. It has been reported that at the transcriptional 448 level, the up-regulation of glucose-repressible ADH2 is a result of an increase in ethanol or acetate 449 production. (Ida et al., 2012; Weinhandl et al., 2014).

In LfeADH2, the sluggishness expression in conjunction with the glucose consumption was expected. When ethanol was high, LfeADH2 expression was derepressed. The derepression state of LfeADH2, however, did not last to the end of fermentation, as ADH2 was immediately repressed through the oxidation of ethanol due to its decline or with the presence of other common fermentation by-products such as acetic acid. In this study, L. fermentati ADH2 derepression by ethanol was pursued with the increase of $\mathrm{ADH} 2$ activity. However, the reason of $\mathrm{ADH} 2$ derepression in glucose remained unclear, as glucose was expected to inhibit the transcription of ADH2. One of the reasons would be because of its high rate in glucose consumption that would contribute to the major decline in $\mathrm{ADH} 2$ expression rather than the concentration itself. In returns, the expression or activity of $\mathrm{ADH} 2$ are more likely to increase when the glucose consumption rate 461 declined and not due to the limitation of glucose in the medium (Table 1S). 
465 cell growth in ethanol. Apparently, the production of ethanol has not improved following the up466 regulations of $\mathrm{LfeADH} 2$ expression. The regulation of ADH2 could be influenced by other co467 expressed genes, such as pyruvate decarboxylase (PDC). PDC plays a role in acetaldehyde 468 formation during the conversion of pyruvate to acetaldehyde, where it may have led to the 469 reduction of ethanol concentration (Ida et al., 2012; Milanovic et al., 2012). This would further 470 promote the down-regulation of $\mathrm{ADH} 2$ expression. Together, the involvement of PDC and ADH2 471 were reported to synergistically promote growth in yeasts by glucose metabolism, as these 472 enzymes were capable of efficiently converting intracellular pyruvate and NADH into ethanol. 473 This event typically occurred in a homoethanol fermentation pathway, also known as the Entner474 Doudoroff(ED) pathway (Piriya et al., 2012). The main difference in the gene expression of ADH2 475 derived from S. cerevisiae and L. fermentati has been the result of ethanol. This could be explained 476 by L. fermentati $\mathrm{ADH} 2$ affinity for ethanol which exhibited lower $\mathrm{K}_{\mathrm{m}}$ compared to S. cerevisiae 477 ADH2 (Table 2).

478 In this observation, the activity of $\mathrm{ADH} 2$ was identical to the transcriptional profiles of 480 ADH2 exhibited over the fermentation course. The bell-shaped curve of ADH2 activity in $L$. 481 fermentati again indicated that $\mathrm{ADH} 2$ transcription was not compelled to the regulation of glucose482 ethanol alone. The increased level of acetic acid might also involve in the regulatory mechanism 483 of $\mathrm{ADH} 2$ gene expression, in which the function of this weak acid was known to retain the redox 484 potential under fermentative condition. 
487 Acetic acid co-production can influence yeast ADH2 activity during cell growth via the metabolic

488 oxidation of carbon sources that generates large amounts of organic acids. To manage the cytosolic

$489 \mathrm{pH}$ homeostasis, the production of acids must be kept in equilibrium with their utilizations

490 (Zdraljevic et al., 2013). As ADH2 involved in the oxidation of ethanol and acetic acid production,

491 it was relevant to determine the correlation between the production of organic acid, particularly of

492 acetic acid, and the changes of $\mathrm{ADH} 2$ activity. The presence of this acid can contribute to the rate-

493 limiting steps in ethanol fermentation although they are produced to retain intracellular $\mathrm{pH}$ in

494 response to glucose availability and to prevent direct inhibition of ethanol via their buffering 495 capacity (Thomas et al. 2002; Ullah et al. 2012).

496

497

498

499

500

501

502

503

504

505

506

507

508

Subsequent experiments performed in glucose fermentation also showed that ADH2 activity was very much regulated by acetic acid produced by L. fermentati (Figure 7A). However, S. cerevisiae ADH2 activity appeared not to be regulated by acetic acid (Figure 7B).

According to Maestre et al., (2008), the overexpression of the ADH2 gene resulting in its high activity during alcohol fermentation would affect the glucose uptakes, cell growth and increased production of acetic acid. It was also reported that this condition was associated to detoxification by removal of acetaldehyde (oxidized product) to restore the intracellular redox potential. Judging by the importance of ADH2 expression in L. fermentati to prevent cell-induced apoptosis, the role of ADH2 could not be ruled out. Acetic acid can easily penetrate the cell wall and induced cell death and one way to decelerate this process is through promoting ADH2 expression or activity (Sousa et al., 2012). Hence, we proposed that acetic acid could be the non- 
509 fermentative carbon source, capable of triggering the regulation of LfeADH2 in glucose

510 fermentation as well as to promote cell growth.

511

512

$\mathrm{ADH} 2$ activity in yeasts come in handy as it has the advantage to promote organic acid and

513 ethanol tolerance and to maintain the relative production of ethanol. In Table 1S, ADH2 activity

514 in L.fermentati was found high in the presence of acetic acid and ethanol. These concentrations

515 were equivalent to $0.835 \mathrm{mmol} / \mathrm{L}$ of acetic acid and $10.62 \mathrm{~g} / \mathrm{L}$ of ethanol when L. fermentati ADH2

516 activity reached its highest level. Subsequently, ADH2 activities subsided when acetic acid was

517 suppressed. Based on these results, we described that the approach of LfeADH2 in gene

518 transcription was not strictly glucose-regulated, as specifically observed in previous experiments

519 performed in most of the wild-type S. cerevisiae (Vallari et al., 1992).

520

521 CONCLUSION

522 Many of the cellular and metabolic features of L. fermentati ADH2 showed protective roles toward

523 intracellular processes during ethanol fermentation. The up-regulation of L. fermentati ADH2 in

524 the presence of glucose and ethanol showed that ADH2 enabled both glucose utilization and

525 ethanol production to occur simultaneously. Acetic acid also is a precursor to ADH2 activity, and

526 L. fermentati has showed to demonstrate a higher tolerance to acetic acid prior to the increase in

527 ADH2 activity. Figure 8 showed a schematic diagram of ADH2 sequence from L. fermentati which

528 plays important role to the cause of gene transcription influencing protein expression during

529 glucose fermentation. Generally, ADH2 has become of practical importance for bioethanol

530 production from L. fermentati, as this gene was highly regulated at the highest level of ethanol

531 fermentation. The mechanism of Adr1-ADH2 binding in L. fermentati can be unique but the 
532 absence of UAS and TATA elements would mean that the gene was unable to be transcribed based

533 on the glucose-repressible condition. Alternatively, the presence of other well-described regulating

534 genes such as Rap1 and Sp1 could be of importance to the activation of L. fermentati ADH2. Based

535 on this preliminary study of $\mathrm{ADH} 2$ from L. fermentati, it is of great interest to describe the

536 mechanism of $\mathrm{ADH} 2$ activation and which type of gene regulations that mostly affect the

537 transcription process. Through this knowledge, the probable use of the ADH2 gene in L. fermentati

538 as a promoter in a facilitating ethanol synthesis from highly rich acetic acid medium of

539 lignocellulosic hydrolysates could be of worth significance.

540

541

REFERENCES

542

543 Bernfeld P. 1955. Amylases $\alpha$ and $\beta$. Methods in Enzymology.1:149-158.

544 Bouwman P, Philipsen S. 2002. Regulation of the activity of Sp1-related transcription factors. 545 Molecular Cellular Endo195: 27-38

546 Burtner CR, Murakami CJ, Kennedy BK, Kaeberlein M. 2009. A molecular mechansim of

547 chronological aging in yeast. Cell Cycle 8: 1256-1270

548 Bustin SA, Benes V, Garson JA, Hellemans J, Huggett J, Kubista M, Mueller R, Nolan T,

549 Pfaffl MW, Shipley GL, Vandesompele J, Wittwer CT. 2009. The MIQE Guidelines:

550 Minimum Information for Publication of Quantitative Real-Time PCR Experiments. Cli Chem

$551 \quad$ (Reviews) 55: 611-622

552 Cheng C, Kacherovsky N, Dombek KM, Camier S, Thukral SK, Rhim E, Young ET. 1994.

553 Identification of potential target genes for Adrlp through characterization of essential 554 nucleotides in UAS1. Mol. Cellular Biol 14:3842-3852 
555 Cho JY, Jeffries TW. 1999. Transcriptional control of ADH genes in the xylose-fermenting yeast $556 \quad$ Pichia stipitis. Appl Environ Microbiol 6: 2363-2368

557 Colabardini AC, Ries LN, Brown NA, Reis TFD, Savoldi M, Goldman MH, Menino JF,

558 Rodrigues F, Goldman GH. 2014. Functional characterization of a xylose transporter in $559 \quad$ Aspergillus nidulans. Biotechnol Biofuels 7: 1-19

560 Denis CL, Ferguson J, Young ET. 1983. mRNA levels for the fermentative alcohol 561 dehydrogenase of Saccharomyces cerevisiae decrease upon growth on a nonfermentable 562 carbon source. J Biol Chem 258: 1165-1171

563 De Smidt O, du Preez JC, Albertyn J. 2012. Molecular and physiological aspects of alcohol 564 dehydrogense in the ethanol metabolism of Saccharomyces cerevisiae. FEMS Yeast Res 12: $33-47$

566 De Smidt O, du Preez JC, Albertyn J. 2008. The alcohol dehydrogenase of Saccharomyces 567 cerevisiae: a comprehensive review. FEMS Yeast Res 8: 967-978

568 Donoviel MS, Kacherovsky N, Young ET. 1995. Synergistic activation of ADH2 expression is 569 sensitive to upstream activation sequence 2 (UAS2) orientation, copy number and UAS1$570 \quad$ UAS2 helical phasing. Mol Cell Biol 15: 3442-3449

571 Fujita S, Senda Y, Nakaguchi S, Hashimoto T. 2001. Multiplex PCR Using Internal Transcribed 572 Spacer 1 and 2 Regions for Rapid Detection and Identification of Yeast Strains. J Cli Microbiol 573 39: $3617-3622$

574 Ida Y, Furusawa C, Hirasawa T, Shimizu H. 2012. Stable disruption of ethanol production by 575 deletion of the genes encoding alcohol dehydrogenase isozymes in Saccharomyces cerevisiae. $576 \quad$ J Biosci Bioeng 113:192-195 
577 Irani M, Taylor WE, Young ET. 1987. Transcription of the ADH2 gene in Saccharomyces 578 cerevisiae is limited by positive factors that bind competitively to its intact promoter region on 579 multicopy plasmids. Mol Cell Bio 7: 1233-1241

580 Ismail KSK, Sakamoto T, Hanusuma T, Kondo A. 2013. Time-based comparative 581 transcriptomics in engineered xylose-utilizing Saccharomyces cerevisiae identifies 582 temperature-responsive genes during ethanol production. J Ind Microbiol Biotech 40: 1039583 1050

584 Kachevrovsky N, Tachibana C, Amos E, Fox D, Young ET. 2008. Promoter Binding by the 585 Adr1 Transcriptional Activator May Be Regulated by Phosphorylation in the DNA-Binding Region. PloS ONE 3: 1-9

Kägi JHR, Vallee BL. 1960. The Role of Zinc in Alcohol Dehydrogenase V. The Effect of Metal Binding Agents in the Structure of the Yeast Alcohol Dehydrogenase Molecule. J Biol Chem 235: $3188-3192$

Kurtzman CP. 2003. Phylogenetic circumscription of Saccharomyces, Kluyveromyces and other members of the Saccharomycetaceae, and the proposal of the new genera Lachancea, Nakaseomyces, Naumovia, Vanderwaltozyma and Zygotorulaspora FEMS Yeast Research.4: 233-245

Lee KM, DaSilva NA. 2005. Evaluation of the Saccharomyces cerevisiae ADH2 promoter for 595 protein synthesis Yeast 22:431-440 dehydrogenases from Kluyveromyces marxianus: heterologous expression in Escherichia coli and biochemical characterization. BMC Biotech 14: 1-10 
599 Lin Y, He P, Wang Q, Lu D, Li Z,Wu C, Jiang N. 2010. The alcohol dehysrogenase system in 600 the xylose-fermenting yeast Candida maltosa. PloS ONE 7: 1-9

601 Maestre O, Garcia-Martinez T, Peinado RA, Mauricio JC. 2008. Effects of $A D H 2$ 602 Overexpression in Saccharomyces bayanus during Alcoholic Fermentation. Appl Environ $603 \quad$ Microbio 74:702-707

604 Milanovic V, Ciani M, Oro L, Comitini F. 2012. Starmerella bombicola influences the 605 metabolism of Saccharomyces cerevisiae at pyruvate decarboxylase and alcohol 606 dehydrogenase level during mixed wine fermentation. Microbial Cell Fact 11: 1-11

607 Nagodawithana TW, Steinkraus KH. 1976. Influence of the rate of ethanol production and 608 accumulation on the viability of Saccharomyces cerevisiae in "rapid fermentation". Appl $609 \quad$ Environ Microbiol. 31: 158-162

610 Natarajan DS, Mohamad R, Rahim RA, Rahman NAA. 2012. Potential of bioethanol 611 production from Nypa fruticans sap by a newly isolated yeast Lachancea fermentati. J Renew $612 \quad$ Sustain Ener 4: 1-10

613 Obradors N, Cabiscol E, Aguilar J, Ros J. 1998. Site-directed mutagenesis studies of the metal614 binding center of the iron-dependent propanediol oxidoreductase from Escherichia coli. Eur. $615 \quad$ J. Biochem 258: 207-213.

616 Piriya PS, Vasan PT, Padma VS, Vidhyadevi U, Archana K, Vennison SJ. 2012. Cellulosic 617 Ethanol Production by Recombinant Cellulolytic Bacteria Harbouring $p d c$ and adh II Genes 618 of Zymomonas mobilis. Biotech Res Int 817549: 1-8

619 Ratnakumar S, Kacherovsky N, Arms E, Young ET. 2009. Snf1 Controls the Activity of Adr1 620 Through Dephosphorylation of Ser230. Genetics 182: 735-745 
621 Ritchie RJ, Prvan T. 1996. Current statistical methods for estimating the Km and Vmax of

622 Michaelis-Menten kinetics. Biochem Edu 24: 196-206

623 Russell PR, Hall BD. The J Biol Chem. 1983. The primary structure of the alcohol 624 dehydrogenase gene from the fission yeast Schizosaccharomyces pombe. 258: 143-149

625 Santangelo GM. 2006. Glucose Signaling in Saccharomyces cerevisiae. Microbiol Molecular 626 Biol Rev 70: 253-282

627 Schaufler LE, Klevit RE. 2003. Mechansim of DNA Binding by the ADR1 Zinc Finger 628 Transcription Factor as Determined by SPR. J Molecular Biol 329: 931-939

629 Seo H-B, Kim H-J, Lee O-K, Ha J-H, Lee H-Y, Jung K-H. 2009. Measurement of ethanol 630 concentration using solvent extraction and dichromate oxidation and its application to 631 bioethanol production process. J Ind Microbiol Biotech 36: 285-292.

632 Suske G. 1999. The Sp-family of transcription factors G. Gene 238: 291-300

633 Thomas KC, Hynes SH, Ingledew WM. 2002. Influence of Medium Buffering capacity on 634 Inhibition of Saccharomyces cerevisiae Growth by Acetic and Lactic Acids. Appl Environ $635 \quad$ Microbiol 68: 1616-1623

636 Thomson JM, Gaucher EA, Burgan MF, Kee DWD, Lee T, Aris JP, Benner SA. 2013. 637 Resurrecting ancestral alcohol dehydrogenases from yeast. Nat Genet. 37: 630-635.

638 Tornow J, Santungelo GM. 1990. Efficient expression of the Saccharomyces cerevisiae 639 glycolytie gene ADHI is dependent upon a cis-acting regulatory element (UASapG) found $640 \quad$ initially in genes encoding ribosomal proteins. Gene. 90: 79-85.

641 Ullah A, Orij R, Brul S, Smits GJ. 2012. Quantitative Analysis of the Modes of Growth Inhibition 642 by Weak Organic Acids in Saccharomyces cerevisiae. Appl Environ Microbiol 78: 8377-8387 
643 Vallari RC, Cook WJ, Audino DC, Morgan MJ, Jensen DE, Laudano AP, Denis CL. 1992.

644 Glucose repression of the yeast $\mathrm{ADH} 2$ gene occurs through multiple mechanisms, including 645 control of the protein synthesis of its transcriptional activator, ADR1. Mol Cell Bio 12: 1663$646 \quad 1673$

647 Wagner JM., Alper HS. 2015. Synthetic biology and molecular genetics in non-conventional 648 yeasts: Current tools and future advances. Fungal Genet Biol. 15: 1087-1845

649 Weinhandl K, Winkler M, Glieder A, Camattari A. 2014.Carbon source dependent promoters 650 in yeasts. Microbial Cell Fact 13: 1-17

651 Young ET, Tachibana C, Chang H-W.E, Dombek KM, Arms EM, Biddick R. 2008. Artificial 652 Recruitment of Mediator by the DNA-Binding Domain of Adr1 Overcomes Glucose 653 Repression of ADH2 Expression. Molecular Cellular Biol 28: 2509-2516

654 Young ET, Sloan J, Miller B, Li N, van Riper K, Dombek KM. 2000. Evolution of a glucose655 regulated ADH gene in the genus Saccharomyces. Gene 245: 299-309

656 Zdraljevic S, Wagner D, Cheng K, Ruohonen L, Jäntti J, Penttilä M, Resnekov O,

657 Pesce CG. 2013. Single-Cell Measurements of Enzyme Levels as a Predictive Tool for 658 Cellular Fates during Organic Acid Production. Appl Environ Microbiol 79: 7569-7582

659 Zhao XQ, Bai FW. 2009. Mechanisms of yeast stress tolerance and its manipulation for efficient 660 fuel ethanol production. J Biotech 144: 23-30

661

662 Figure legend

663

664 Figure 1.Glucose and ethanol induction on ADH2 from $S$. cerevisiae and $L$. fermentati . ADH2 665 activity in $S$. cerevisiae (Sce) and L. fermentati (Lfe) after induction with $2 \%\left(\mathrm{wv}^{-1}\right)$ glucose (A) 
666 and $0.5 \%\left(\mathrm{vv}^{-1}\right)$ ethanol (B). Qualitatively, the ADH2 activity staining was performed on the non-

667 denaturing polyacrylamide gels with respective lanes indicated as 1 (before induction) and 2 (after

668 induction). All experiments have been repeated twice for validation.

669

670 Figure 2 Multiple ClustalW alignment of ADH2 peptide sequences of Lachancea fermentati

671 SHM1 (KU203771), Kluyveromyces marxianus (BAP71734.1), Kluyveromyces lactis

672 (CAA45739.1), Lachancea kluyveri (AAP51047.1), Lachancea lanzarotensis (CEP60577.1),

673 Lachancea thermotolerans CBS 6340 (XP_002555715.1), Saccharomyces bayanus

674 (AAP51043.1), Saccharomyces cerevisiae YJM451 (AJS66970.1), Saccharomyces kudriavzevii

675 (EJT43588.1) and Saccharomyces pastorianus (AAP51051.1). The red box showed amino acid

676 alignment of zinc-binding site $(\mathrm{HXXXH)}$ present in the medium-chain NAD (P)-dependent

677 dehydrogenase. While the blue-box contained the sequences of NAD (P)-binding domain having

678 the motifs of SLEGGEV and KATNGG used for gene expression. The N-terminal of ADH2 gene

679 from Lachancea fermentati strain SHM1 starts at residue 29-137, while the C-terminal starts at 680 residue 180-304 based on Interpro (EMBL-EBI) analysis.

681

682 Figure 3 Neighbor-joining phylogenetic analysis separating the sequences of ADH2 from $L$. 683 fermentati in Lachancea ADH2 family and Saccharomyces/Kluyveromyces ADH2 family 684 groups. Clustering was performed via the neighbour-joining method using Pearson model with 685 the software package, MEGA (Molecular Evolutionary Genetics Analysis) version 6.06. The 686 percentages at the nodes indicate the levels of bootstrap support for the branch point based on 1000 687 bootstrap replicates.

688 
689 Figure 4 Multiple nucleotide sequence alignment of Pichia stipitis (Y13397.1), Saccharomyces

690 cerevisiae S288c (NM_001182812.1), Kluyveromyces marxianus (KF678866.1) and Lachancea

691 fermentati SHM1 (KU203771). The presence of UAS sequences (5'-GGAGA-3') was identified

692 in a purple box and TATA elements were captured in blue box. Three transcription genes were

693 identified as Sp1 (11) in orange-colored box, Rap1 (3) in red-box and Adr1 (3) represented in

694 green-colored box.

695

696 Figure 5. The fractionation of regulatory transcription genes present in ADH2 gene from

697 Lachancea fermentati strain SHM1 (in percentage).

698

699 Figure 6. The profiles of ADH2 gene expression measured by real time PCR and ADH2

700 activity determination based on protein reaction with ethanol on both $S$. cerevisiae and $L$.

701 fermentati. Fig $6 \mathrm{~A}$ and $6 \mathrm{~B}$ exhibited the relative $\mathrm{ADH} 2$ gene expression, whereas Fig 6C and 6D

702 exhibited the ADH2 activity of each protein extracted from S. cerevisiae and L. fermentati

703 respectively, under similar fermentation state.

704

705 Figure 7. Effect of acetic acid production on the ADH2 activity from L. fermentati (A) and

S. cerevisiae (B) glucose fermentation

707

708

Figure 8.Schematic diagram describing the role of ADH2 gene from Lachancea

fermentati strain SHM1 in the regulation of glucose, ethanol and organic acid in bioethanol

710

fermentation

711 
712 Tables

713

714 Table 1 List of the primers for ADH2 gene amplifications and one reference gene for the

715 normalization of the gene expression studies. ACT1* was selected as the reference gene for 716 normalization.

717

718 Table 2 Enzyme kinetics of crude alcohol dehydrogenase (ADH) from $L$. fermentati and $S$.

719 cerevisiae. Assays were carried out at $25^{\circ} \mathrm{C}$ and the absorbance at $340 \mathrm{~nm}$ was measured. Assays

720 were performed in triplicates per single run. $V_{\text {Max and }} K_{M}$ were calculated based on the half-

721 reciprocal, Hanes-woolf equation (Ritchie and Prvan, 1996).

722

723

724 


\section{1}

Glucose and ethanol induction on ADH2 from S. cerevisiae and L. fermentati.

ADH2 activity in S. cerevisiae (Sce) and L. fermentati (Lfe) after induction with $2 \%\left(w v^{-1}\right)$ glucose (A) and $0.5 \%\left(\mathrm{Vv}^{-1}\right)$ ethanol (B). Qualitatively, the $\mathrm{ADH} 2$ activity staining was performed on the non-denaturing polyacrylamide gels with respective lanes indicated as 1 (before induction) and 2 (after induction). All experiments have been repeated twice for validation.
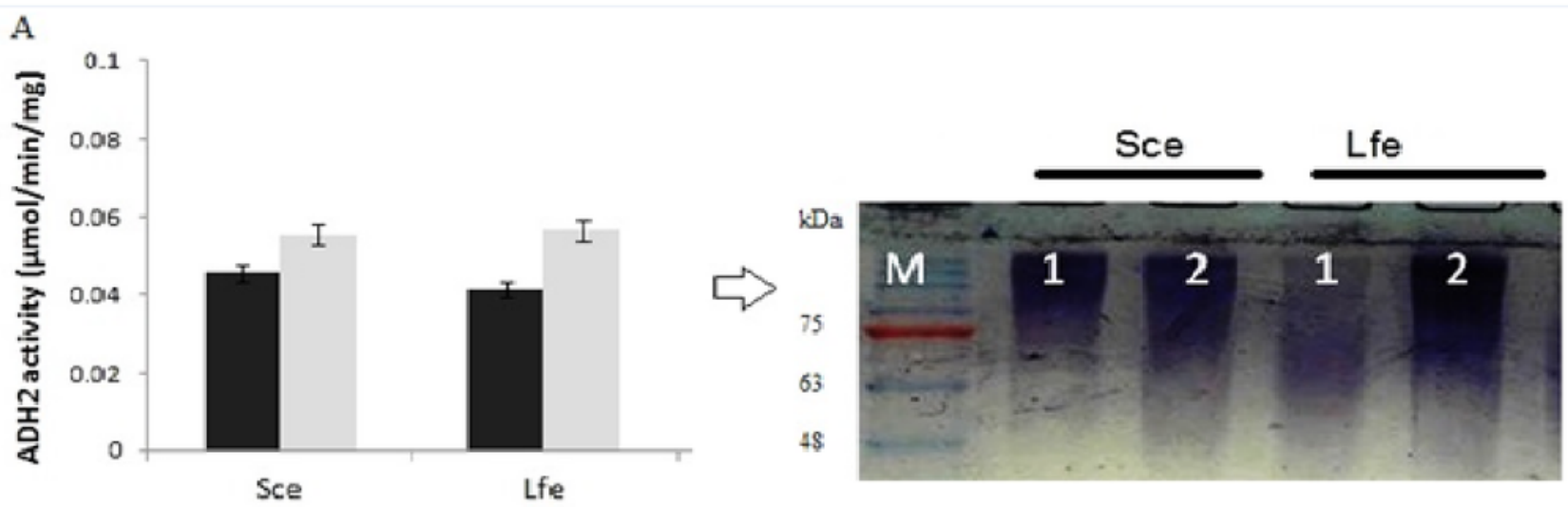

- Before glucose induction After glucose induction

B

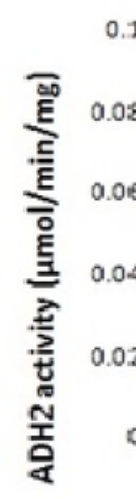

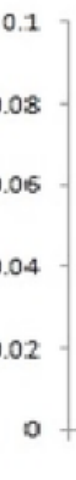
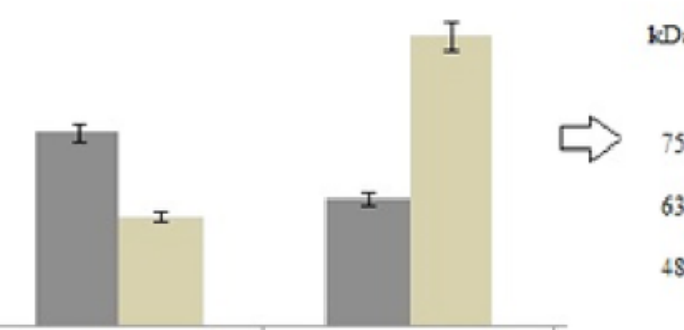

$\mathrm{Da}$

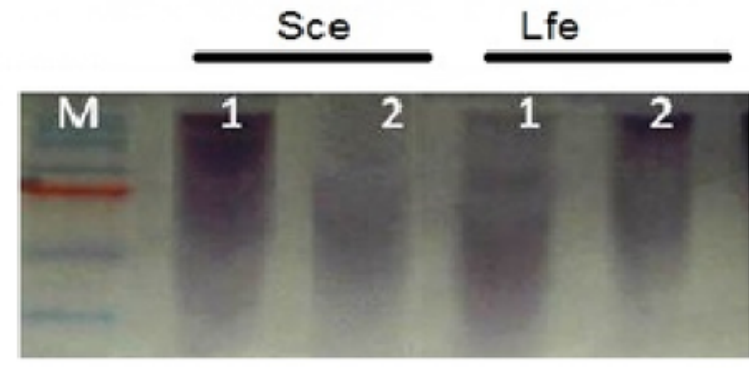

Sce 


\section{2}

Multiple ClustalW alignment of $\mathrm{ADH} 2$ peptide sequences

The red box showed amino acid alignment of zinc-binding site (HXXXH) present in the medium-chain NAD (P)-dependent dehydrogenase. While the blue-box contained the sequences of NAD (P)-binding domain having the motifs of SLEGGEV and KATNGG used for gene expression. The N-terminal of ADH2 gene from Lachancea fermentati strain SHM1 starts at residue 29-137, while the C-terminal starts at residue 180-304 based on Interpro (EMBLEBI) analysis.

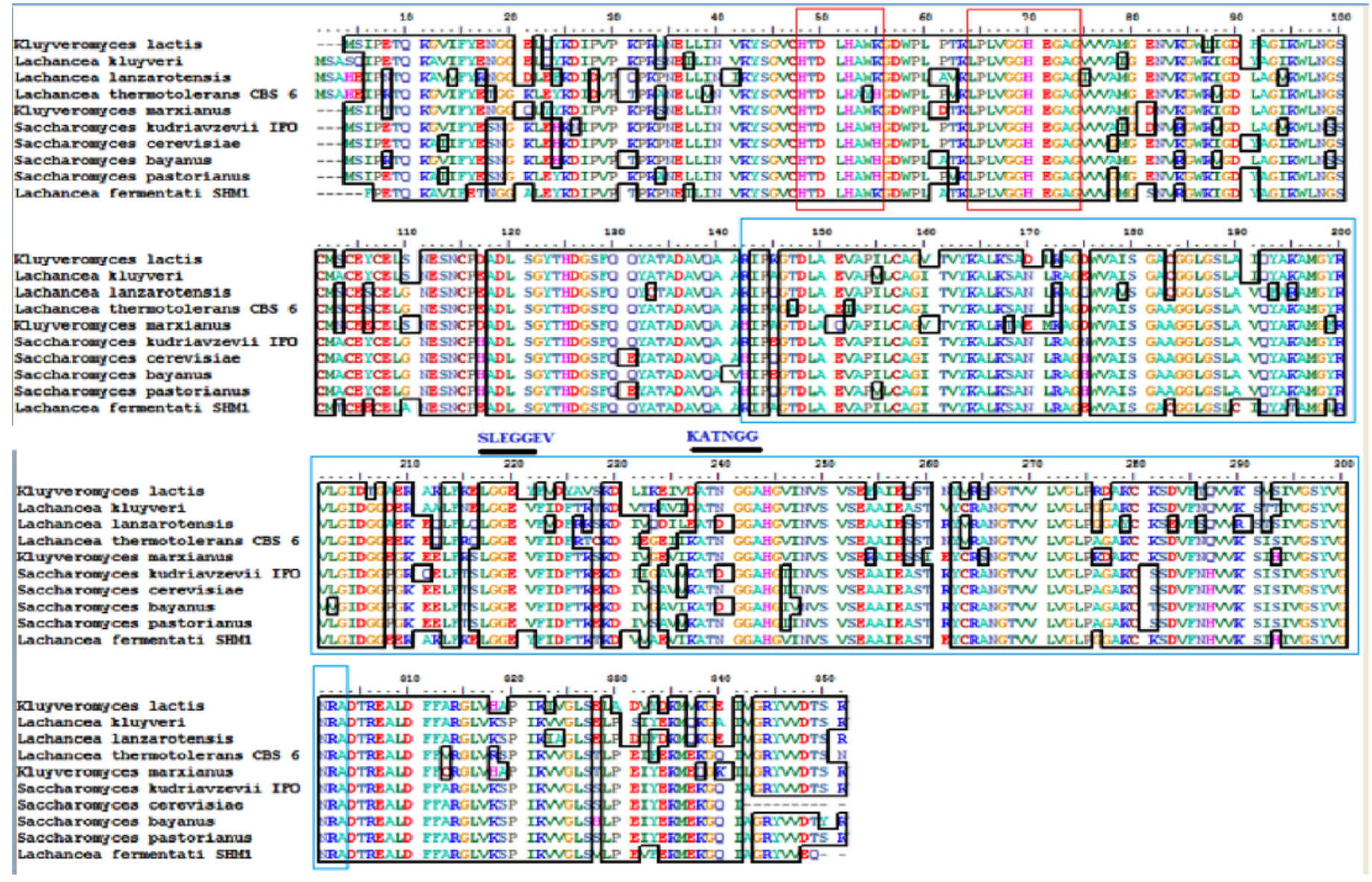




\section{3}

Neighbor-joining phylogenetic analysis separating the sequences of $A D H 2$ from $L$. fermentati in Lachancea ADH2 family and Saccharomyces/Kluyveromyces ADH2 family groups.

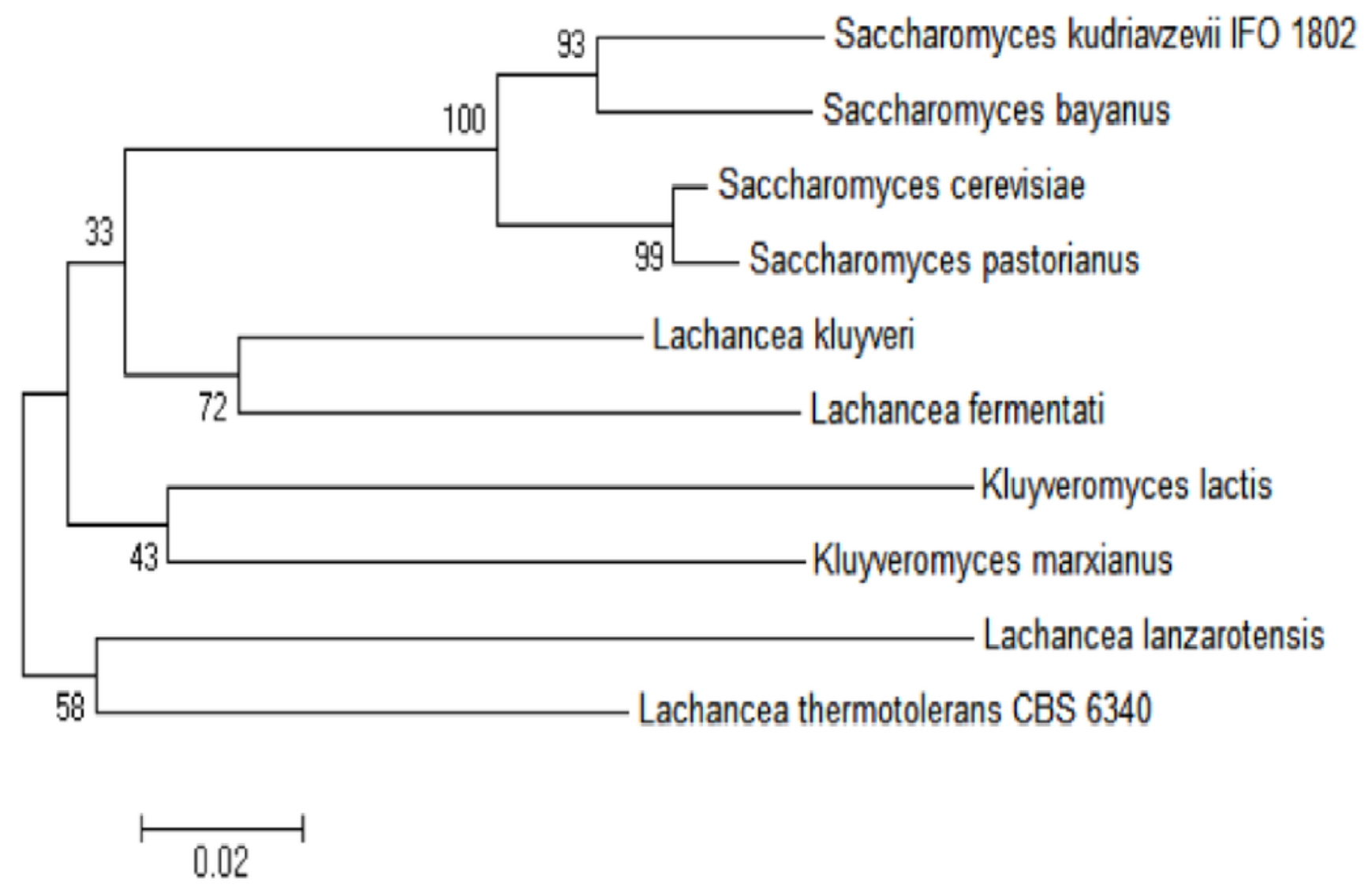


4

Multiple sequence alignment of Pichia stipitis (Y13397.1), Saccharomyces cerevisiae (NM_001182812.1), Kluyveromyces marxianus (KF678866.1) and Lachancea fermentati (KU203771).

The presence of UAS sequences (5'-GGAGA-3') was identified in a purple box and TATA elements were captured in blue box. Three transcription genes were identified as Sp1 (11) in orange-colored box, Rap1 (3) in red-box and Adr1 (3) represented in green-colored box. 
Kluyveronyces narxianus $\mathrm{CX}-\mathrm{tw1}$ Lachancea termentats sher Diehia atipitia saceharempers cerevioial sabe

XLyveremyees parxianus CX-UNi Lachances Eermentati siert Dichia stipitin

Saceharenyces cerevialae s2abe

KLuyveromyces marxianus, CX-UNi Lachancea termentati SHMI Diehia atipieis

Sacehurenjees cervviaiae sabe

XLuyverengees marxianus CX-CDi Lachances Eerrentati siect Dichia otipitis

Sacehuronyces cerevioiae sabe

Kiuyveromyces narxianus, CX-GOI Lachancea termentati SHMI Diehia atipieia

Saceharemyees cervvisiae sabe

Ruyveremyees marxianus GX-COHI Cachancea fermentati siot:

Pichia otipitis

saccharonyces cerevisiae s2abe

Cluyveronyces marxianus GX-Git: Cachancea termentati stous Diehia stipieis

Bacehuremyces ceroviaiae sabe

Cluyveromyees marxianus CX-CON1 Lechances fermentati slot: Pichia otipitis

saccharomyces cerevialae sabe

Clayveromyces marxianu, GX-GT: Cachancea fermentati stors Diehia seipieis

sucehuromyees cervisalae sabe

Cuyvercenyees marxianus CX-Cor: Lechunees sermentati siots Pichia otipitis

jaccharonyces cerevisiae s2bie

Kluyvercmyces marxisnus ex-tat! Lachancea fermentati sion: Dichia stipieis

Sucehareayens cerevisiae s28Be

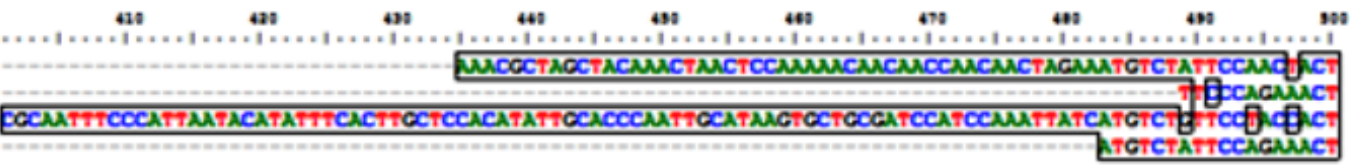

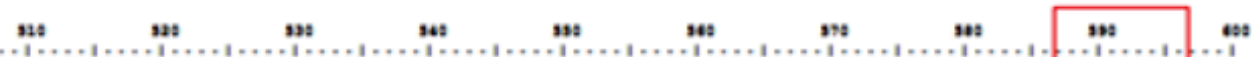
एWUCC E eur coccole

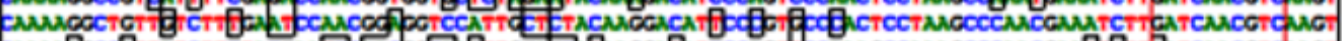

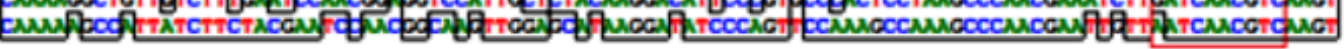

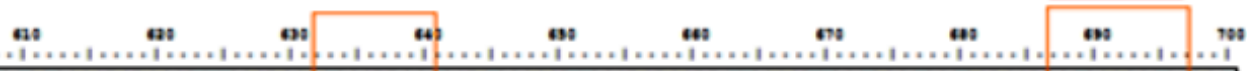

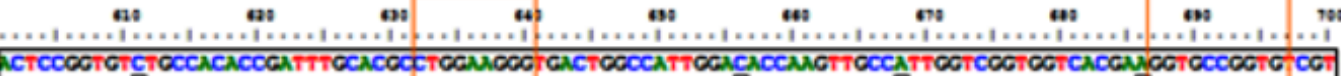

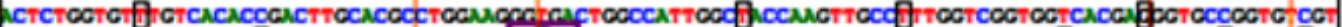

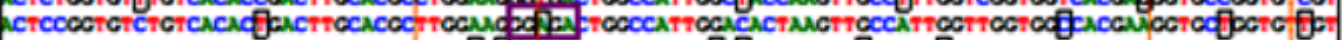

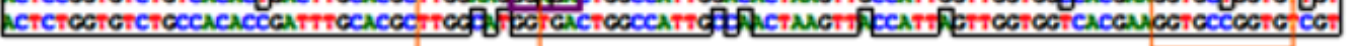

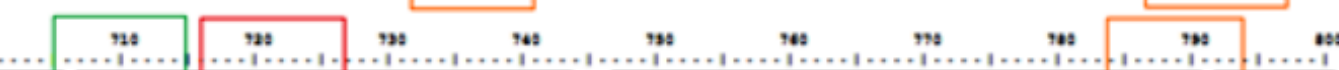
EGFC

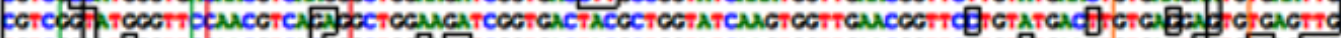

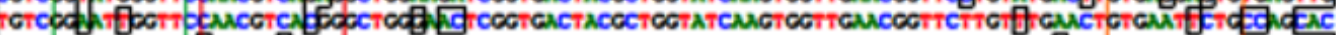

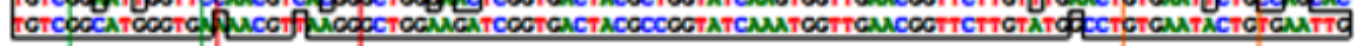

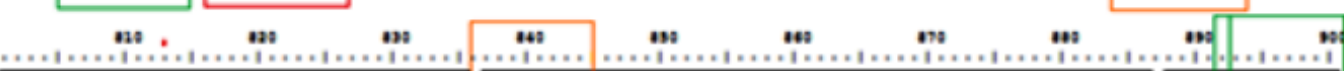

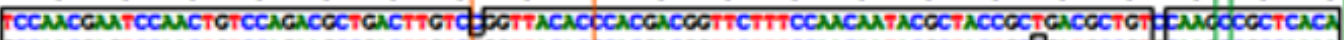

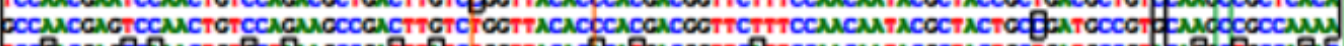
rco f

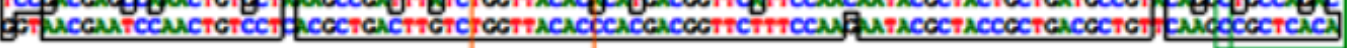

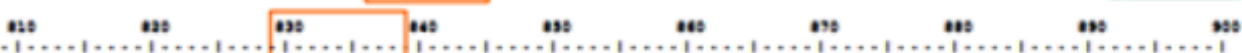

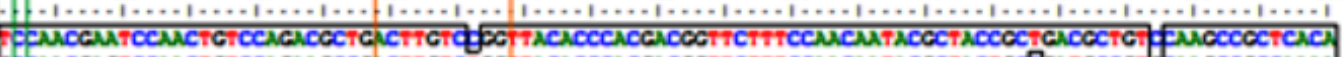

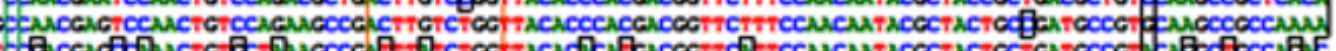

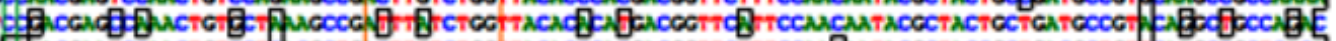

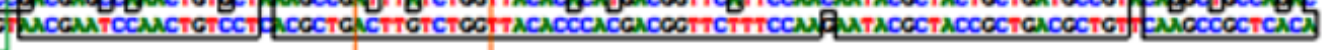

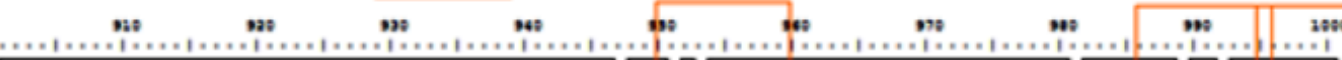

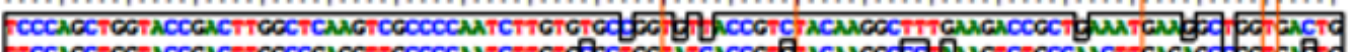

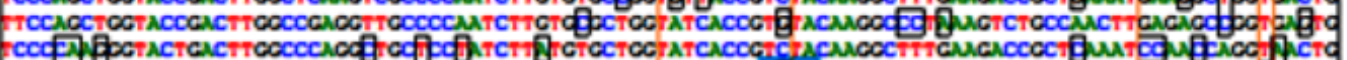

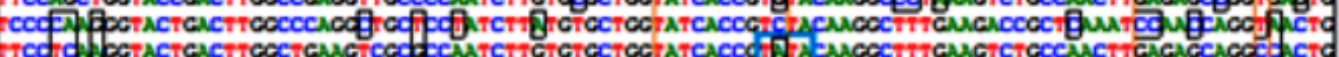

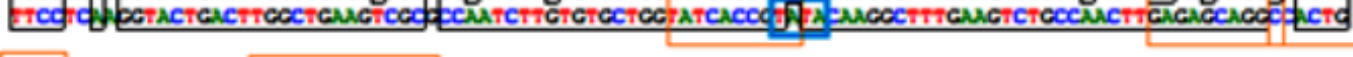

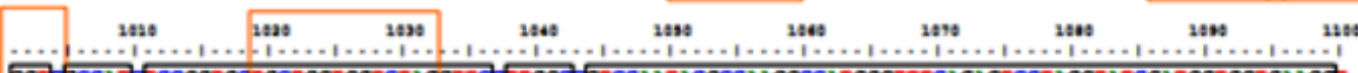

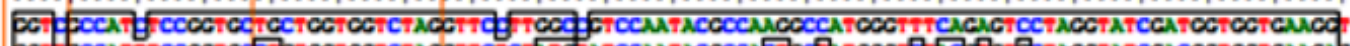

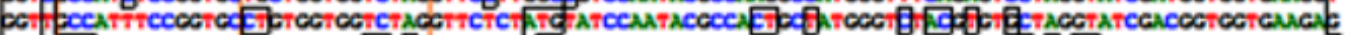
60j

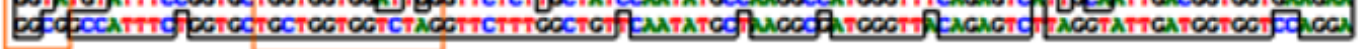

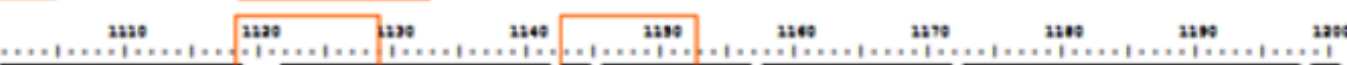
MCGMGATTGTCAg uhoc

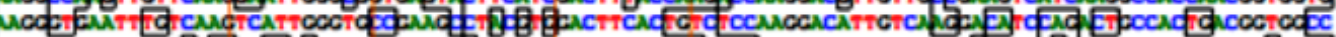

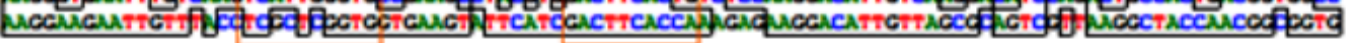

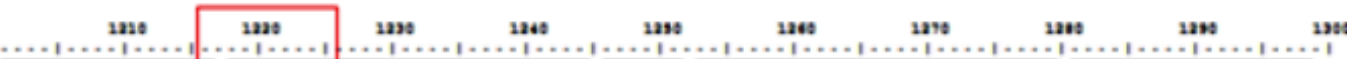

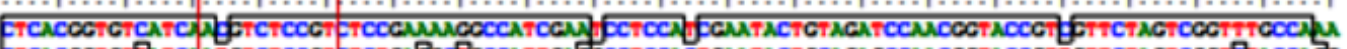
Frencogrc

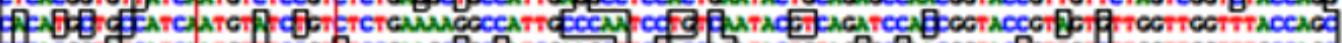

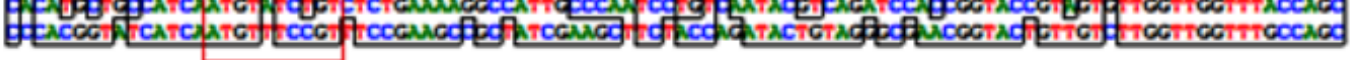

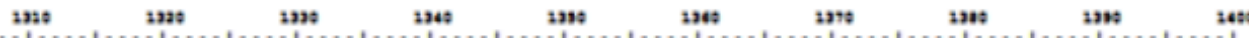

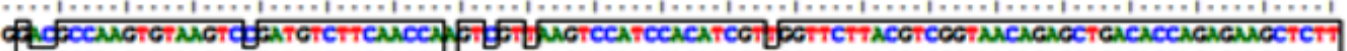

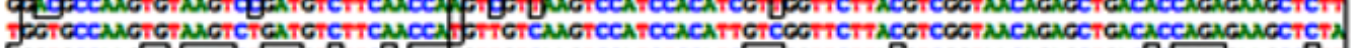

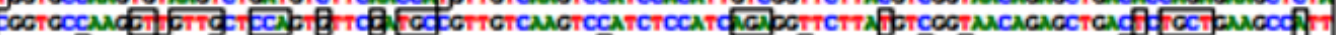

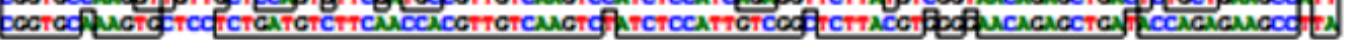




\section{5}

The fractionation of regulatory transcription genes present in ADH2 gene from Lachancea fermentati strain SHM1 (in percentage)

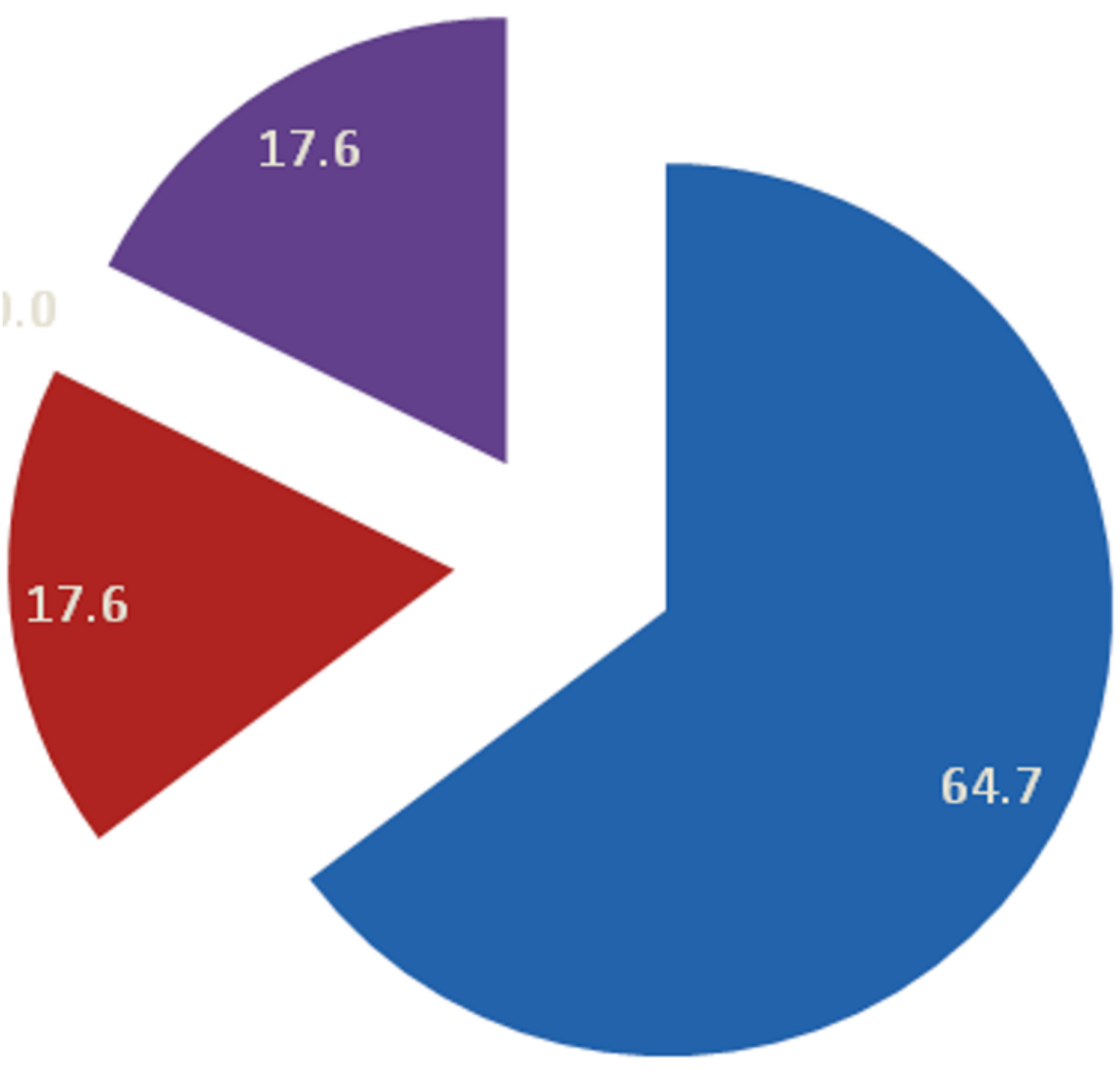

-Other repression and activation Transcription (SP1)

$\square \mathrm{ADH} 2$ activation and for dycerol metabolism (Adr1)

Glycolysis transcription and expression(RAP1) 
6

The profiles of $A D H 2$ gene expression measured by real time PCR and ADH2 activity determination based on protein reaction with ethanol on both $S$. cerevisiae and $L$. fermentati.

Fig $6 \mathrm{~A}$ and $6 \mathrm{~B}$ exhibited the relative $\mathrm{ADH} 2$ gene expression, whereas Fig $6 \mathrm{C}$ and $6 \mathrm{D}$ exhibited the ADH2 activity of each protein extracted from S. cerevisiae and L. fermentati respectively, under similar fermentation state.

A

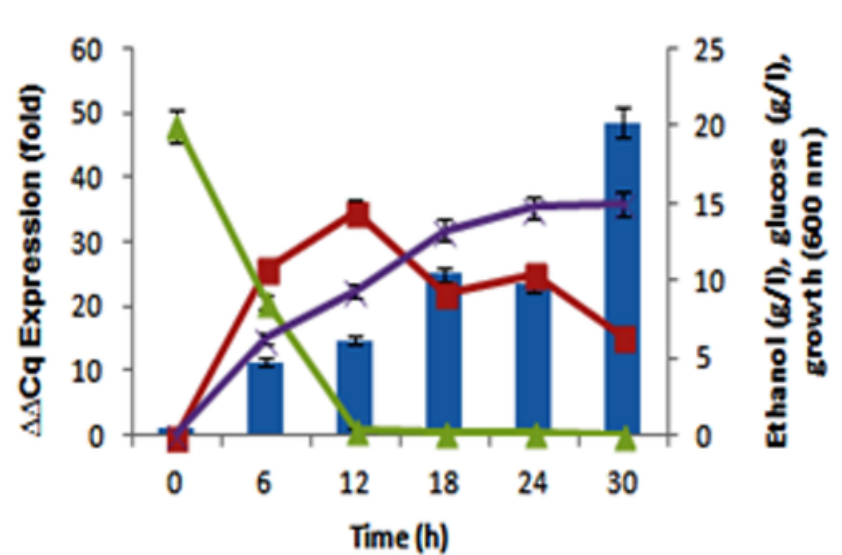

B

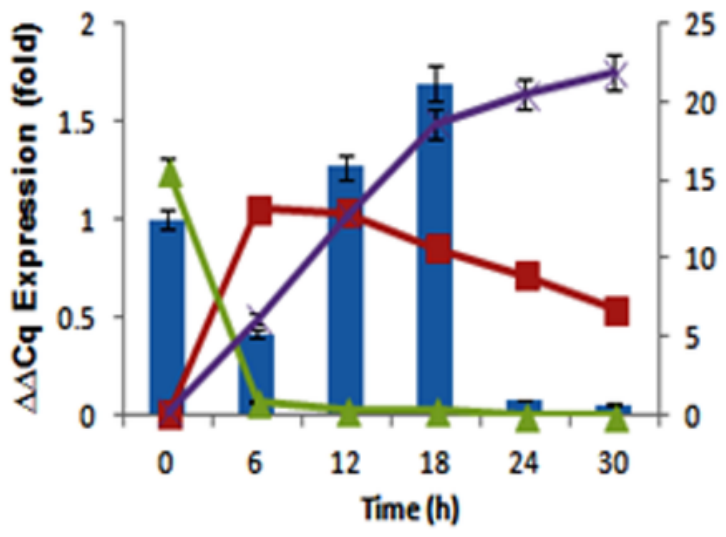

C
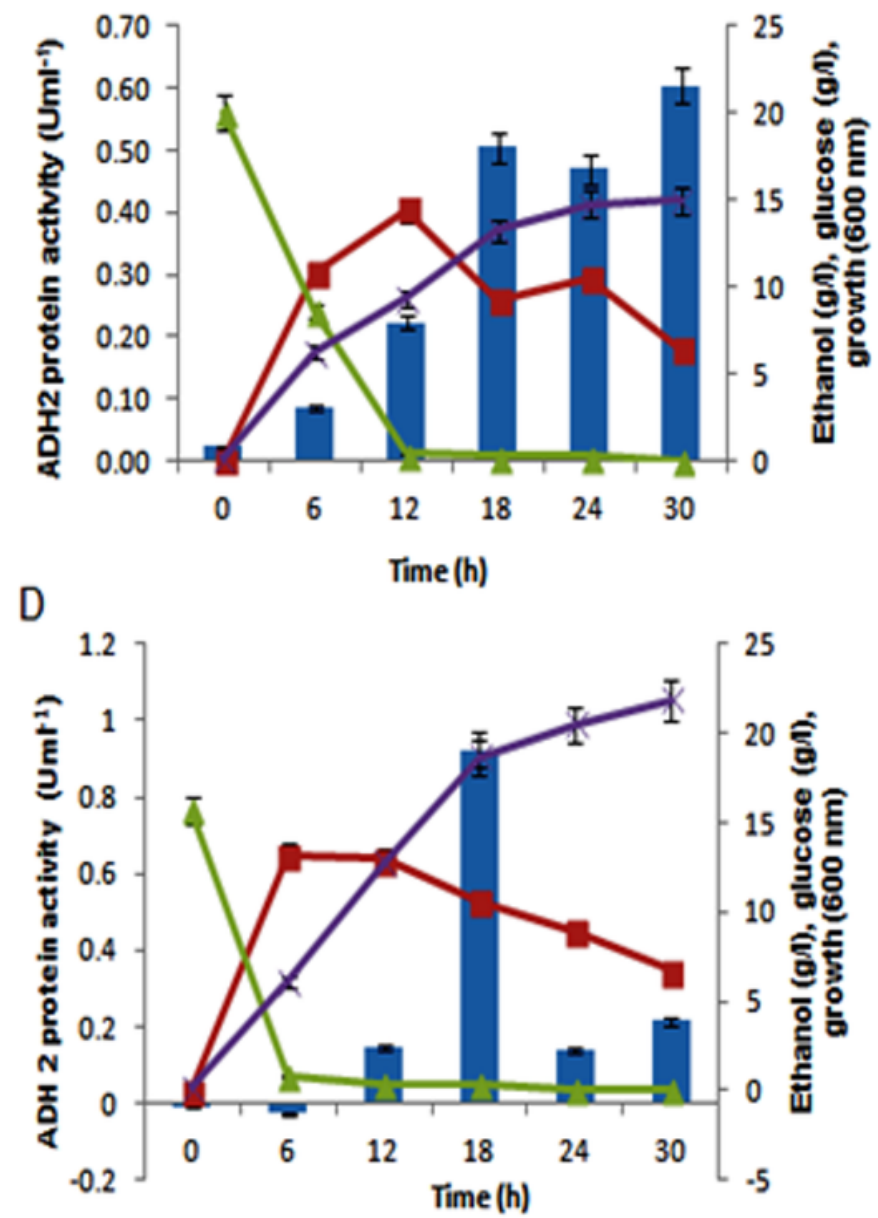

ADH2 activity/ expression $\rightarrow$ Ethanol $\quad \pm$ Glucose $\quad$ Growth 
7

Effect of acetic acid production on the $A D H 2$ activity from $L$. fermentati $(A)$ and $S$. cerevisiae (B) glucose fermentation.
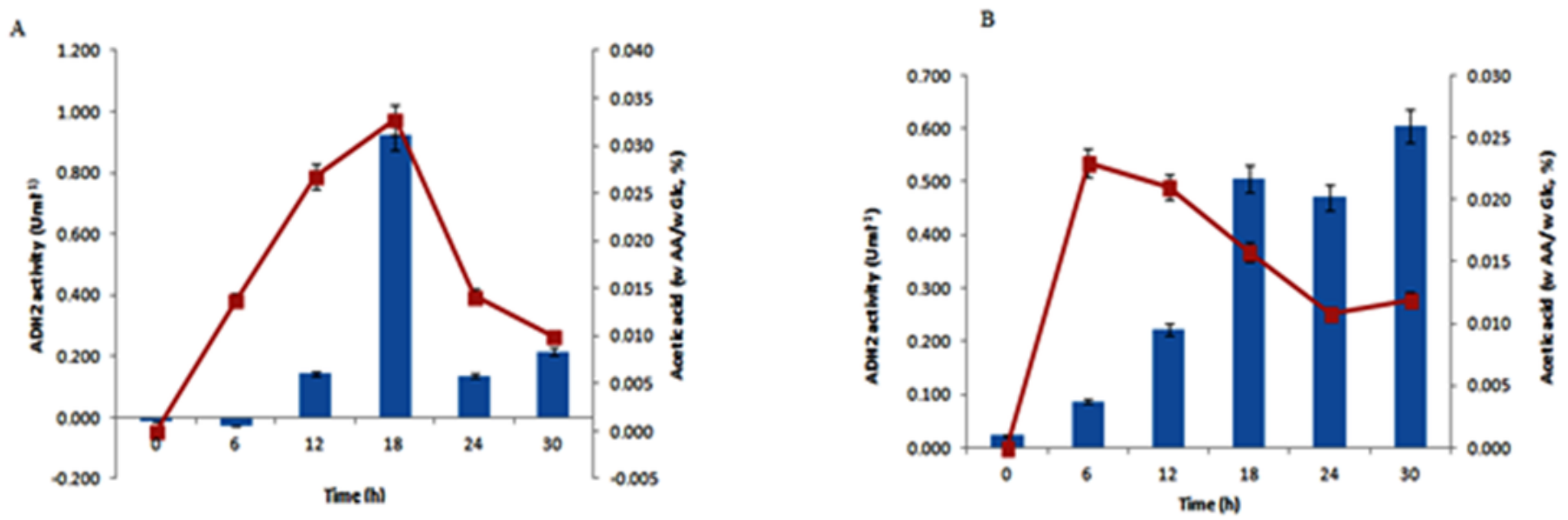
8

Schematic diagram describing the role of $\mathrm{ADH} 2$ gene from Lachancea fermentati strain SHM1 in the regulation of glucose, ethanol and organic acid in bioethanol fermentation

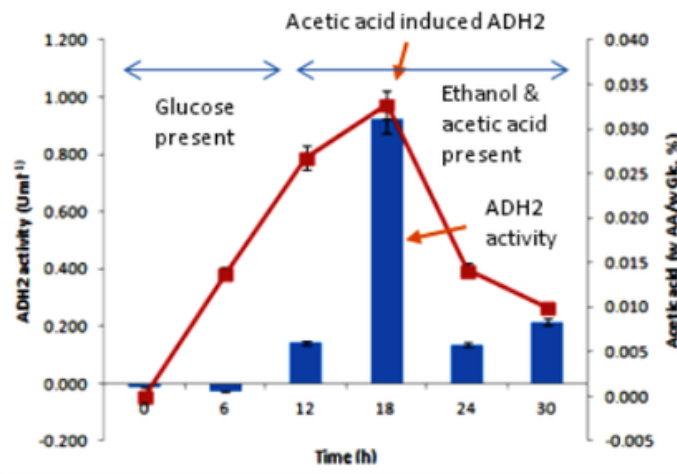

Adr1 (3 sites), Rap-1 (3 sites) and Sp-1 (11

sites) are present in $A D H 2$ gene sequence from Lachancea fermentati

Induction with glucose

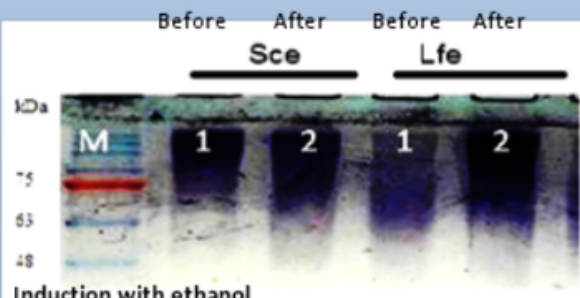

Induction with ethanol

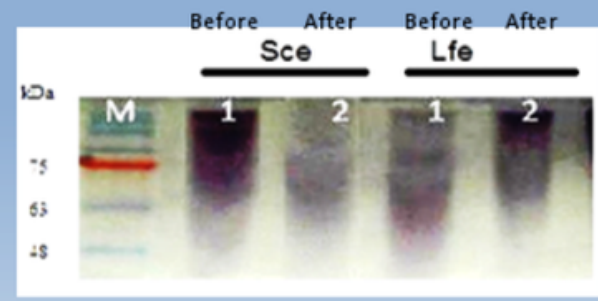

Ethanol and acetic acid more significant for ADH2 repression/derepression in $L$. fermentati?

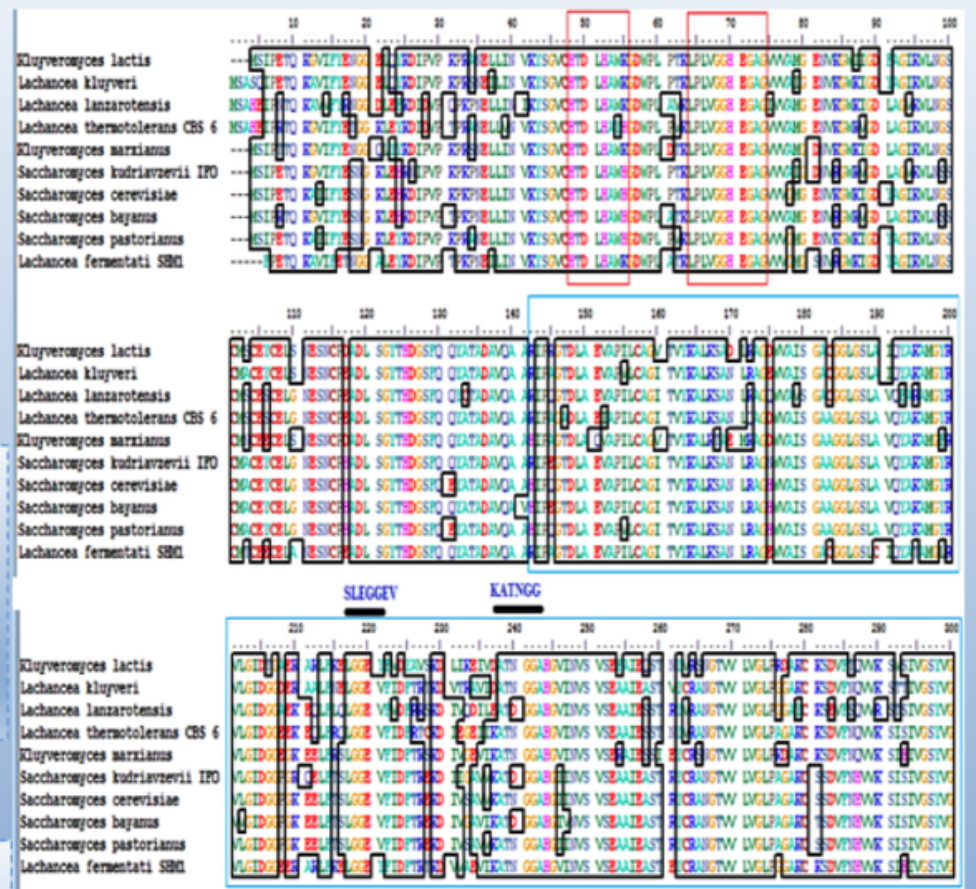
glucose even it
Saccharomyces cerevisiae ADH2 was observed not strongly repressed in possessedUAS Adr1-binding sites and TATA

motifs.

fermentati: Lack in UAS binding sites and TATA motifs in ADH2 caused derepression in glucose.$$
\text { sistions }
$$

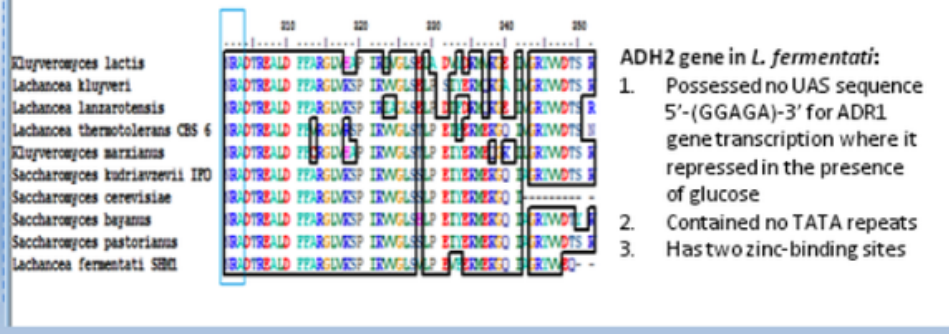




\section{Table $\mathbf{1}$ (on next page)}

List of the primers for ADH2 gene amplifications and one reference gene for the normalization of the gene expression studies.

ACT1* was selected as the reference gene for normalization. 
$1 \quad$ Table 1

\begin{tabular}{lllll}
\hline No. & Primer & Sequence $\left(5^{\prime}-3^{\prime}\right)$ & Start (bp) & Stop (bp) \\
\hline
\end{tabular}

1. Degenerate primer amplification based on Lachancea kluyveri ADH2 (accession no. AAP51047.1) gene sequence for unknown ADH2 gene isolation from L. fermentati strain SHM1 (to provide sequence template for selected gene targets)

$\begin{array}{llccc}\text { ForADH2 } & \text { ATYCCAGAAACTCAAAARGCCRTTA } & 538 & 565 & 52.5 \\ \text { RevADH2 } & \text { TGTCRACAACGTATCTACCRRCAAT } & 1547 & 1572 & 59.3\end{array}$

2. Real time RT-PCR primer sequences (derived from sequences from partial amplified ADH of respective strain)

i SceADH2_F CGCAGTCGTTAAGGCTACCAA SceADH2_R CGATAGCGGCTTCGGAAAC 760

$\begin{array}{cc}710 & 59 \\ 742 & 59 \\ 673 & 62 \\ 699 & 66.3\end{array}$

ii LfeADH2_F GACTTTACCAAGACCAAGG

655

720

56

56

iii ACT1_F * TGGATTCCGGTGATGGTGTT TCAAAATGGCGTGAGGTAGAGA 


\section{Table 2 (on next page)}

Enzyme kinetics of crude alcohol dehydrogenase (ADH) from L. fermentati and S. cerevisiae.

All assays were carried out at $25^{\circ} \mathrm{C}$ and the absorbance at $340 \mathrm{~nm}$ was measured. Assays were performed in triplicates per single run. $\mathrm{V}_{\text {Max and }} \mathrm{K}_{M}$ were calculated based on the halfreciprocal, Hanes-woolf equation (Ritchie and Prvan, 1996). 
Table 2

$\begin{array}{lllll}\text { Substrate } & \mathrm{K}_{\mathrm{M}}(\mathrm{mM}) & \operatorname{Vmax}\left(\mathrm{umol} \mathrm{mg}^{-}\right. & \mathrm{K}_{\text {cat }}\left(\mathrm{s}^{-1}\right) & \mathrm{K}_{\text {cat }} / \mathrm{K}_{\mathrm{M}}\left(\mathbf{M}^{-1} \mathbf{s}^{-1}\right)\end{array}$

$\left.1 \mathrm{sec}^{-1}\right)$

\begin{tabular}{|c|c|c|c|c|c|}
\hline SceADH2 & ethanol & $0.28 \times 10^{2}$ & $0.8 \times 10^{-2}$ & $1.18 \times 10^{-2}$ & $42.54 \times 10^{-2}$ \\
\hline LfeADH2 & ethanol & $5.08 \times 10^{2}$ & $1.3 \times 10^{-2}$ & $3.86 \times 10^{-2}$ & $7.60 \times 10^{-2}$ \\
\hline
\end{tabular}

5

6 